\title{
A Simulation-Optimization System to Assess Dam Removal With a Focus on Environmental Degradations at Downstream
}

Mahdi Sedighkia ( $\square$ mahdi.sedighkia@my.jcu.edu.au )

James Cook University

Asghar Abdoli

Esri

\section{Research Article}

Keywords: dam removal, aquatics habitats, optimal reservoir operation, ANFIS, PSO

Posted Date: June 8th, 2021

DOI: https://doi.org/10.21203/rs.3.rs-493680/v1

License: (c) (i) This work is licensed under a Creative Commons Attribution 4.0 International License.

Read Full License 


\section{A simulation-optimization system to assess dam removal with a focus on} environmental degradations at downstream

(1)

1- Researcher, College of science and engineering, James Cook University, Townsville, QLD, Australia

2- Professor, Environment science research institute, Velenjak, Tehran, Iran

*Corresponding Author: Mahdi.sedighkia@my.jcu.edu.au

\section{Abstract}

The present study proposes and evaluates an integrated framework to assess dam removal in which downstream river habitats and reservoir operation were simulated in three different statuses including conventional reservoir operation optimization, optimal release considering environmental aspects in the structure of the optimization model and natural flow. Fuzzy physical habitat simulation was used to assess physical habitats. Moreover, ANFIS based model was utilized to simulate thermal tension and dissolved oxygen tension at downstream habitats. Particle swarm optimization was applied in the optimization models. Results of the optimization models and habitat suitability in the natural flow were compared by applying different measurement indices including reliability index, vulnerability index, The Nash-Sutcliffe model efficiency coefficient (NSE) and root mean square error (RMSE). Based on the results in the case study, reliability of water supply might be reduced in the optimal release for environment and demand. Furthermore, optimal release for environment is not able to protect downstream aquatics habitats properly. Thus, if protecting downstream habitats is aimed, dam removal might be logic in the case study. The main limitation of the proposed method is high computational complexities.

Keywords: dam removal, aquatics habitats, optimal reservoir operation, ANFIS, PSO

\section{1-Introduction}

Rivers have a significant role to supply water demand including drinking demand and irrigation demand. Large dams are the most important hydraulic structures in the rivers where are mainly 
responsible for water supply. Moreover, they might have other rules such as electricity supply and flood control (Altinbilek, 2002). Increasing population might raise environmental challenges for the river ecosystems (Postel, 1998). On the one hand, required water demand is increased that means more offstream flow is needed. On the other hand, instream flow is decreased that means increasing environmental degradation in the river ecosystems. Environmental impacts of the dams have been highlighted in the literature in the recent decades (e.g Tahmiscioğlu et.al, 2007). Owing to importance of the river ecosystems and other possible impacts of these structures, dam removal is one of the challenging issues that has been focused in the recent years. Previous studies discussed regarding importance and feasibility of the dam removal projects (e.g Bednarek, 2001; Foley et.al, 2017; Major ert.al, 2017). It seems that different aspects must be considered in the dam removal. Thus, complex modeling might be needed in this regard. An integrated framework is helpful to assess how dam removal might be advantageous for the environment. Many aspects might be considered in the analysis of the dam removal. However, impacts on the aquatic habitat at downstream is one of the effective aspects in the assessment of the dam removal projects.

Dams are very expensive hydraulic structures. Hence, optimal reservoir operation was highlighted in the literature as the most critical task after construction of the reservoirs (Ahmad et.al, 2014). In fact, a reservoir should have an optimal operation to maximize benefits. Hashimoto et,al 1982 developed an applicable form of the loss function that has widely been used for the optimization system of the reservoirs. Moreover, Datta and Burges, 1984 highlighted adding storage loss to the optimization system as well. This form of loss function has been used even in the recent studies due to applicability and efficiency (Ehteram ert.al, 2018). On the other hand, optimization solution is another principal aspect in the reservoir operation models. Many methods such as linear programming (LP), non-linear programming (NLP) and dynamic programming (DP) have been applied in this regard (e.g Reis et.al, D., 2006; Arunkumar and Jothiprakash, 2012). However, LP methods are not efficient due to non-linear nature of the reservoir operation. NLP and DP might not be efficient due to complexities of the defined objective function. Hence, advanced computational methods such as metaheuristic algorithms have been utilized and recommended in many recent studies. A long list of the classic and new generation 
algorithms have been highlighted to optimize reservoir operation (e.g Afshar et.al, 2007; Afshar et.al, 2011; Yaseen et.al, 2019). Previous studies have pointed out that animal and non-animal inspired algorithms might be useful for reservoir operation optimization (Jahandideh-Tehrani et.al, 2019).

Assessing environmental degradation in the rivers needs some tools. Mathematical models might be useful tools in this regard that are able to assess water quality and quantity in a river. Abiotic factors are effective to provide suitable habitats for the aquatics in the rivers (Ahmadi-Nedushan et.al, 2006). It should be noted that aquatics are a good environmental index for assessing the river ecosystem that has been recommended and used as the target species in the previous studies (Yao and Chen, 2018). Abiotic factors including physical parameters and water quality parameters are taken into account for different environmental issues such as environmental flow assessment (Ahmadi-Nedushan et.al, 2006). Effective physical parameters consist of depth, velocity and substrate that were the basis of forming the concept of physical habitat simulation (Waddle, 2001). Univariate methods are the simplest approach to simulate physical habitats in which suitability of depth, velocity and substrate is assessed separately. Then, a mathematical model such as multiply, minimum or geometric mean is utilized to compute the combined habitat suitability (Vismara et.al, 2001). However, this method has been criticized in the literature due to absence of ability to consider interactions between physical factors (Noack et.al, 2013). Hence, the more efficient methods such as fuzzy multivariate method has been developed to assess physical habitats in the recent decades. This method is able to consider interactions between physical factors that is mainly based on expert opinions (Noack et.al, 2013). It should be noted that expert opinion might play key role in the physical habitat simulation due to complexities of the physical habitat selection by the fishes.

Water quality is another aspect in the river ecosystem management. Because, lack of water quality suitability might harm aquatics drastically. In fact, many biological activities of the aquatics are depended on the appropriateness of the water quality parameters including temperature, dissolved oxygen etc (Devi et.al, 2017). For example, many fish species need to immigrate to the upstream of the rivers for the reproduction process that guarantees the survival of the species for a long-term period. However, many fishes such as the Brown trout are such sensitive to the water temperature and level of 
the dissolved oxygen. Lack of suitable water temperature or dissolved oxygen might be a serious hindrance for the reproduction process (Eklöv et.al, 1999). Hence, considering water quality is essential in each environmental management plan of the river ecosystem.

Present study proposes and evaluates an integrated framework to assess dam removal with a focus on the downstream environmental degradations. In fact, we developed a novel framework to assess dam removal in which physical and water quality simulation are applied in the structure of the reservoir operation optimization. The proposed method provides an applicable path to assess the environmental advantages of dam removal in an integrated framework. In fact, this method might respond to stakeholders and environmental advocators questions regarding dam removal. The proposed method responds to this principal question how dam removal might reduce environmental degradation at the downstream river habitats. Moreover, it demonstrates how an optimal operation considering environmental degradation in the structure of the optimization might help to reduce impacts on the downstream river habitats. Present study might open a new window to improve simulation-optimization methods to assess dam removal projects that provides an upgradable and flexible framework.

\section{2- Application and methodology}

The proposed framework consists of two scenarios in which reservoir losses and environmental degradation at downstream are measured. Then, different measurement indices will be carried out to determine how dam removal might be advantageous for the environment and how it might reduce benefits for the society in the river basin. In the first scenario, release and storage in the reservoir are optimized without considering environmental flow at downstream which assesses the highest benefits from the reservoir in related to the release and storage. In the second scenario, a novel optimization system is proposed in which environmental degradation and reservoir losses are minimized simultaneously. Moreover, it assumes that dam is removed to assess river in natural flow. Physical and water quality suitability are assessed in the natural flow as well. In the case study, it was assessed how dam removal affects the river basin. The proposed framework could be used in each case study with 
some minor changes and technical consideration related to the case study. Some simulations, assessments and optimizations are required to implement the proposed framework that are presented as follows.

\section{2-1-physical habitat simulation}

111 Physical habitat simulation is used to assess physical habitat suitability in different developed scenarios 112 as explained in the previous section. Previous studies indicate applicability of this simulation for the river ecosystem management (Sedighkia et.al, 2017). Figure 1 displays workflow of the physical habitat simulation in the present study. We applied 1D fuzzy physical habitat simulation, which is one of the most efficient methods for physical habitat assessment. It should be noted that previous studies corroborated the applicability and efficiency of the one-dimensional hydraulic modelling for the physical habitat simulation (Jowett and Duncan, 2012). Development of the fuzzy habitat rules is the most important step in the physical habitat simulation. We used a combination of the field studies and expert opinions to develop fuzzy rules. Field studies consist of two main parts including ecological studies or fish observations and surveying the river cross-sections that is required for hydraulic simulation. Several methods have been developed for the fish sampling in the rivers including direct and indirect methods. Discussion on advantages and disadvantages of each method have been presented in the literature (Harby et.al, 2004). Electrofishing was used in the present study due to its advantages and previous experiences of the research team regarding this method. Moreover, depth and velocity were measured in the microhabitats simultaneously by the propeller and metal rule (Harby et.al, 2004). It should be noted that the Brown trout was considered as the target species in the case study. A representative reach with length of 1000 meters was considered in the physical habitat simulation. 


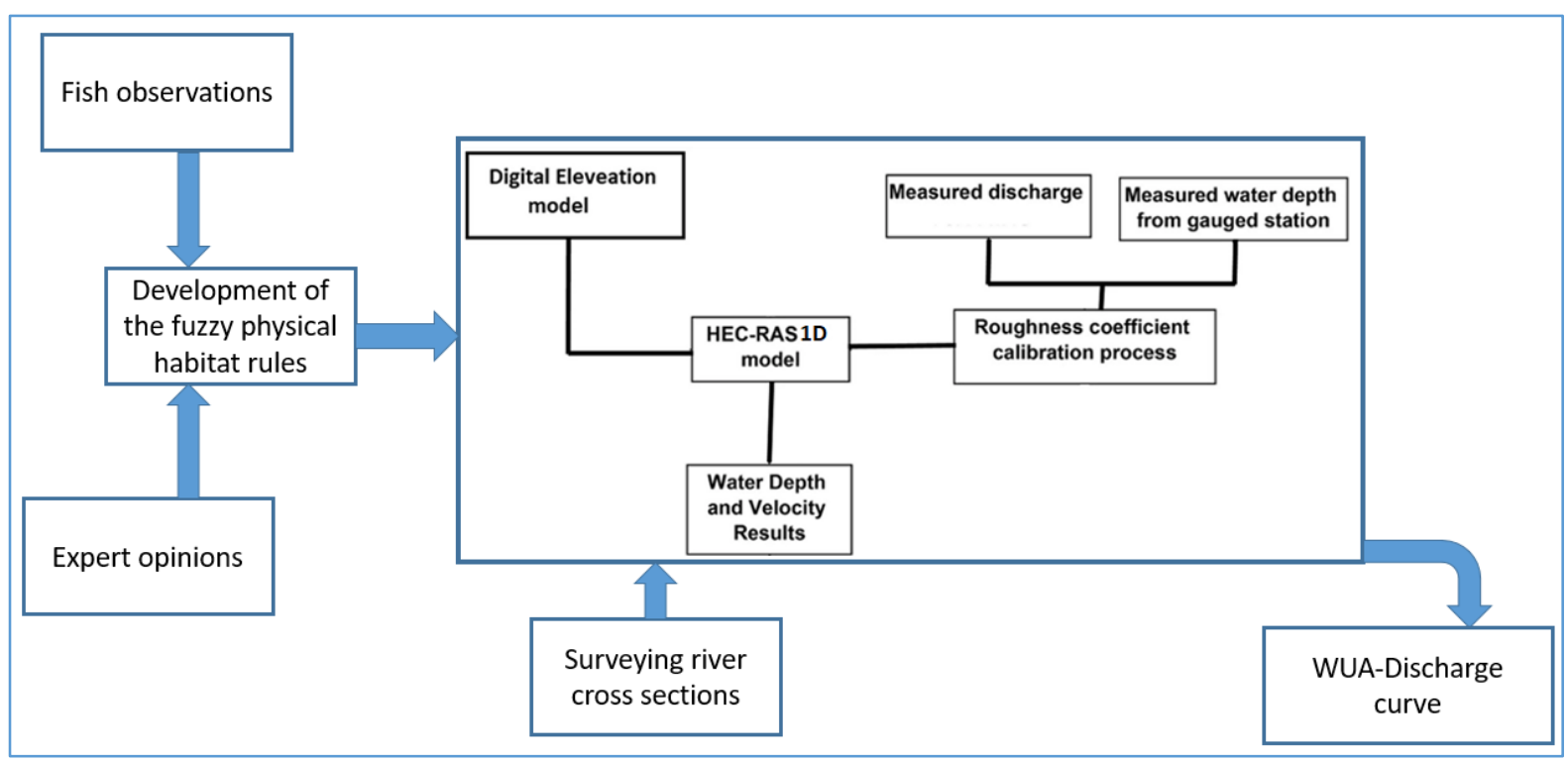

Figure 1- flowchart of the physical habitat simulation in the proposed framework

\section{2-2-thermal habitat assessment}

Thermal habitat assessment is another requirement in the proposed framework to analyse dam removal.

The first need to achieve this purpose is to simulate stream temperature. Hydrodynamic models such as SSTEMP has been developed to simulate stream temperature (Bartholow, 2000). However, they are not flexible to apply in the structure of the optimization model. Hence, we need a flexible and applicable method. Data driven models are one of the efficient options in this regard. We developed a new data driven model to simulate stream temperature at downstream of the reservoir. Using neural networks is one of the most applicable methods to develop a robust data driven model in the water quality simulation (e.g Chatterjee et.al, 2017). Owing to inherent disadvantages of the artificial neural networks (ANN) such as working as black box, combining fuzzy inference system and neural network might generate the higher efficiency (Dumitru and Maria, 2013). Hence, we utilized an adaptive neuro fuzzy inference system (ANFIS) to simulate stream temperature in the proposed framework (developed by (Jang, 1993). Figure 2 displays a simple structure of the ANFIS based model in which two inputs were considered. More details on the responsibility of each layer is available in literature (Awan and Bae, 2014). Table 1 displays main characteristics of the developed ANFIS based model to simulate stream temperature. As displayed, several inputs are considered in the model that demonstrates data driven stream temperature model might be complex. In the next step, it is required to convert stream temperature to 
the thermal habitat tension. Sedighkia et,al 2019 used a biological based model to asses thermal habitat tension of the Brown trout that has been adopted in the present framework. It should be noted that using other target species might need its own thermal tension model. Figure 3 displays thermal tension curve for the Brown trout that was used in the case study. It should be noted that optimization system was used in the monthly scale. Thus, we applied recorded monthly data in different stations at the downstream. Moreover, using an index is essential to measure the robustness of the data driven model. The Nash-Sutcliffe model efficiency coefficient (NSE) was used in this regard which has initially been developed for measuring performance of hydrological models (Gupta et.al, 2009). However, it is useable for any types of the simulation to compare results with recorded data or observation for validating the model. equation 1 displays basic form of this index. A relationship between wetted perimeter and discharge was developed based on hydraulic modelling by HEC-RAS 1D to estimate wetted perimeter in the optimization model. Downstream reach with length of 9000 meters was considered in the stream temperature modelling. In the equation $1, \mathrm{~m}_{\mathrm{t}}$ is simulated or modelled parameter, $\mathrm{O}_{\mathrm{t}}$ is observed or recorded data, $\mathrm{O}_{\text {mean }}$ is average of the observed data. Ti is number of samples.

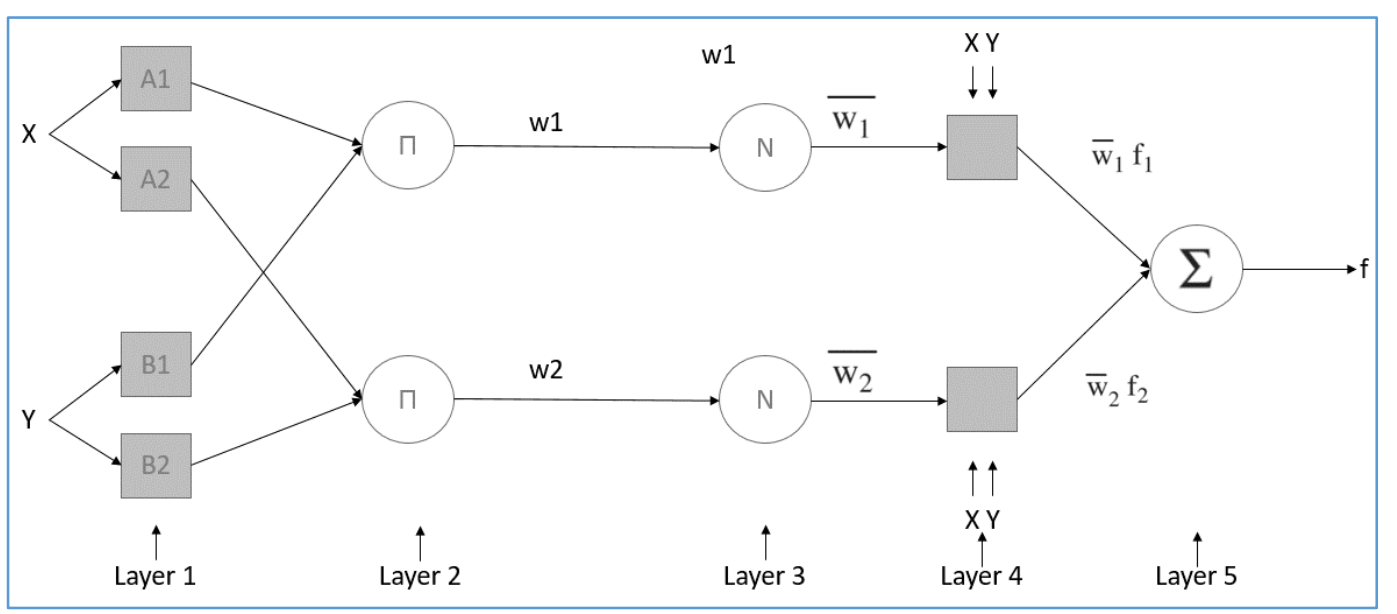

Figure 2-Simple structure of ANFIS based data driven model 


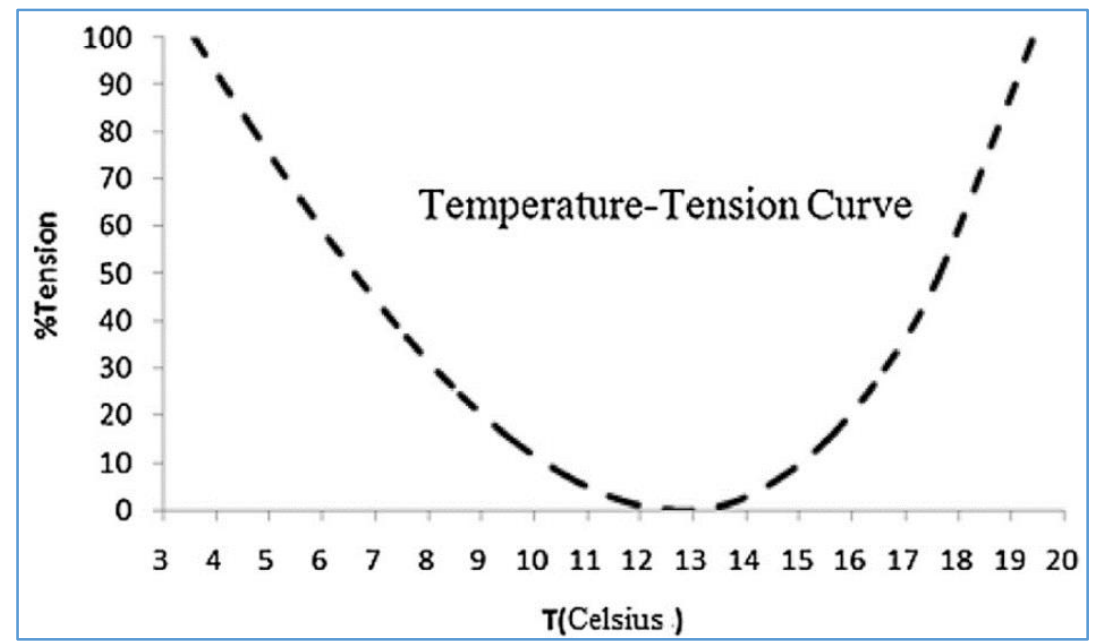

Figure 3- Temperature tension curve developed Sedighkia et,al 2019

Table 1-Main characteristics of ANFIS based data stream temperature model

\begin{tabular}{|c|c|c|c|c|c|c|}
\hline Inputs & $\begin{array}{l}\text { Number } \\
\text { of MFs } \\
\text { (inputs) }\end{array}$ & $\begin{array}{c}\text { Type of } \\
\text { MFs } \\
\text { (inputs) }\end{array}$ & Outputs & $\begin{array}{c}\text { Number of } \\
\text { MFs } \\
\text { (Output) }\end{array}$ & $\begin{array}{c}\text { Type of } \\
\text { MFs } \\
\text { (Output) }\end{array}$ & $\begin{array}{c}\text { Clustering } \\
\text { method }\end{array}$ \\
\hline flow rate $(\mathrm{cms})$ & 10 & Gaussian & Water & 10 & Linear & Subtractive \\
\hline Wetted perimeter(m) & 10 & Gaussian & temperature & & & Clustering \\
\hline $\begin{array}{c}\text { Distance from the } \\
\text { reservoir }\end{array}$ & 10 & Gaussian & $\begin{array}{l}\text { at each } \\
\text { cross }\end{array}$ & & & \\
\hline $\begin{array}{c}\text { Elevation level from } \\
\text { the Sea }\end{array}$ & 10 & Gaussian & section & & & \\
\hline $\begin{array}{l}\text { Water temperature at } \\
\text { distance }=0 \mathrm{~m}\left({ }^{\circ} \mathrm{c}\right)\end{array}$ & 10 & Gaussian & & & & \\
\hline Air temperature $\left({ }^{\circ} \mathrm{c}\right)$ & 10 & Gaussian & & & & \\
\hline
\end{tabular}




\section{2-3-Dissolved oxygen modelling}

Dissolved oxygen is an important water quality factor for the river habitats that might shows suitability of water quality for the aquatics. Because, other pollutants might affect the concentration of the DO in the river. Thus, we selected DO as the representative for all of the water quality parameters. We used ANFIS based model to simulate concentration of the dissolved oxygen as well. Monthly scale was considered in this data driven models. Table 2 displays main characteristics of the developed data driven model for simulating dissolved oxygen. DO is depended on the other water pollutants that might be drained in the river. Hence, we considered month (Jan to Dec) as one of the inputs in the data driven model. It should be noted that rate of pollutants is changed in different months due to agricultural activities at the downstream river basin. Sedighkia et.al 2019 developed a DO tension model for the Brown trout as well that was adopted in the proposed framework. In fact, outputs of the DO model were converted to the DO tension by the biological model. Figure 4 displays DO tension curve developed by Sedighkia et.al 2019 that was utilized in the case study. We applied NSE to measure robustness of the dissolved oxygen data driven model as well.

Table 2-Main characteristics of ANFIS based data dissolved oxygen model

\begin{tabular}{|c|c|c|c|c|c|c|}
\hline Inputs & $\begin{array}{l}\text { Number } \\
\text { of MFs } \\
\text { (inputs) }\end{array}$ & $\begin{array}{l}\text { Type of } \\
\text { MFs } \\
\text { (inputs) }\end{array}$ & Outputs & $\begin{array}{l}\text { Number of } \\
\text { MFs } \\
\text { (Output) }\end{array}$ & $\begin{array}{c}\text { Type of } \\
\text { MFs } \\
\text { (Output) }\end{array}$ & $\begin{array}{c}\text { Clustering } \\
\text { method }\end{array}$ \\
\hline Month (Jan to Dec) & 10 & Gaussian & dissolved & 10 & Linear & Subtractive \\
\hline Rate of flow (cms) & 10 & Gaussian & oxygen at & & & Clustering \\
\hline $\begin{array}{c}\text { Distance from the } \\
\text { reservoir }\end{array}$ & 10 & Gaussian & $\begin{array}{l}\text { each cross } \\
\text { section }\end{array}$ & & & \\
\hline $\begin{array}{l}\text { Water temperature } \\
\text { at each cross section } \\
\qquad\left({ }^{\circ} \mathrm{c}\right)\end{array}$ & 10 & Gaussian & & & & \\
\hline
\end{tabular}




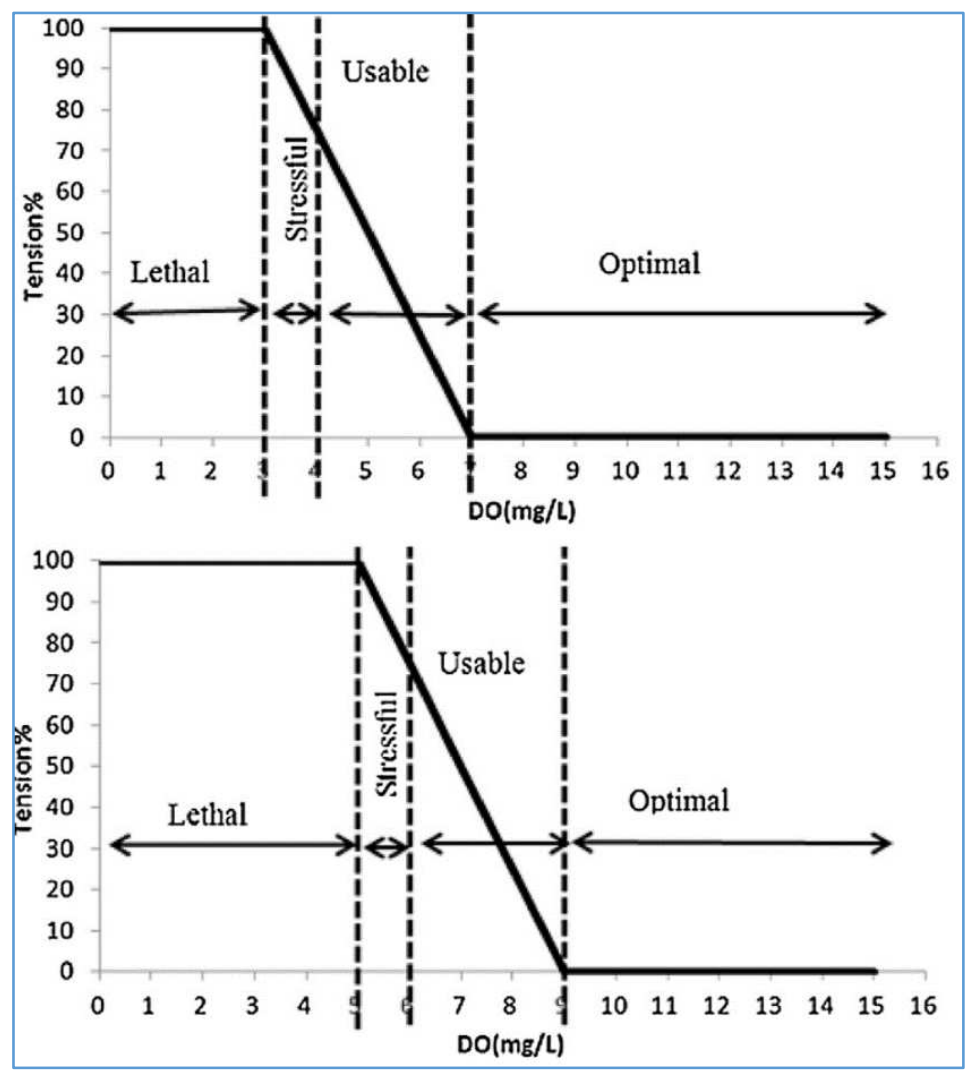

Figure 4- Dissolved oxygen tension curve developed Sedighkia et,al 2019- Up: water temperature $<15^{\circ \mathrm{cc}}$ Down: water temperature $>15^{\circ \mathrm{c}}$

\section{2-4- optimization model}

In the both scenarios, we need optimization models that are able to optimize reservoir operation. In the first scenario that generates the highest benefits from the reservoir, equation 2 was used as the objective function. This loss function minimizes different between target (maximum requested water demand) and release for demand. Each optimization model might need some constraints in its structure. We considered some constraints in the proposed optimization model for the scenario 1 including minimum operational storage, maximum storage and maximum water demand. In fact, storage in the reservoir should not be less than minimum operational storage and more than capacity of the reservoir. Moreover, release for demand should not be more than maximum requested water demand. We focused on the metaheuristic optimization as an efficient solution for the optimization process. Penalty function is one the known methods to handle constraints in the metaheuristic optimization that has been used in many previous studies (developed by Agarwal and Gupta, 2005). Three penalty functions were considered in 
the optimization model for the scenario 1 as follows. In fact, these penalty functions increase penalty for the model when the constraints are violated in the optimal solution. Equation 6 displays final form of the objective function for the optimization model in the scenario $1 . \mathrm{C} 1$ to $\mathrm{C} 3$ are constant coefficients that were determined based on initial sensitivity analysis of the optimization model.

$O F=\sum_{t=1}^{T}\left(\frac{D_{t}-R_{t}}{D_{t}}\right)^{2}$

if $S_{i}>S_{\max } \rightarrow P 1=c 1\left(\frac{S_{t}-S_{\max }}{S_{\max }}\right)^{2}$

if $S_{i}<S_{\min } \rightarrow P 2=c 2\left(\frac{S_{\min }-S_{t}}{S_{\min }}\right)^{2}$

if $R_{t}>D_{t} \rightarrow P 3=c 3\left(\frac{R_{t}-D_{t}}{D_{t}}\right)^{2}$

$\operatorname{Minimize}(O F)=\sum_{t=1}^{T}\left(\frac{D_{t}-R_{t}}{D_{t}}\right)^{2}+P 1_{t}+P 2_{t}+P 3_{t}$

where $\mathrm{D}_{t}$ is maximum water demand, $\mathrm{R}_{t}$ is release for demand or total release for environment and demand in the scenario $2, S_{t}$ is storage, $S_{\max }$ is maximum storage or capacity of the reservoir and $S_{\min }$ is minimum operational storage in the reservoir. Moreover, it is necessary to update reservoir storage in each time step that was carried out by the equation 7 . Overflow was calculated by the equation 8 where $E_{t}$ is evaporation from the reservoir, $A_{t}$ is area of the reservoir, $I_{t}$ is inflow of the reservoir and $T$ is time horizon.

$S_{t+1}=S_{t}+I_{t}-R_{t}-\left(\frac{E_{t} \times A_{t}}{1000}\right), t=1,2, \ldots, T$

$\left\{\begin{array}{c}\text { if }\left(S_{t}+I_{t}-\left(\frac{E_{t} \times A_{t}}{1000}\right)\right) \geq S_{\max } \rightarrow F_{t}=S_{t}+I_{t}-\left(\frac{E_{t} \times A_{t}}{1000}\right)-S_{\max } \\ \text { if }\left(S_{t}+I_{t}-\left(\frac{E_{t} \times A_{t}}{1000}\right)\right)<S_{\max } \rightarrow F_{t}=0\end{array}\right.$

We developed a novel optimization model for the scenario 2 in which water demand loss, storage loss and environmental degradation are minimized. Hence, loss function used in the previous optimization model is one of the terms in this optimization model. In fact, four main terms were considered including water demand loss, physical habitat loss, and thermal habitat loss and dissolved oxygen loss as follows 
.PHN, THN and DHN are normalized weighted useable area, thermal suitability and dissolved oxygen suitability in the natural flow respectively. PHM, THM and DHM are normalized weighted useable area, thermal suitability and dissolved oxygen suitability in the optimal release for environment respectively.

$O F=\sum_{t=1}^{T}\left(\frac{D_{t}-R_{t}}{D_{t}}\right)^{2}+\left(\frac{P H N_{t}-P H M_{t}}{P H N_{t}}\right)^{2}+\left(\frac{T H N_{t}-T H M_{t}}{T H N_{t}}\right)^{2}+\left(\frac{D H N_{t}-D H M_{t}}{D H N_{t}}\right)^{2}$

229 We utilized penalty function method in this optimization model as well. Used penalty functions were 230 the same. Final form of the objective function for the optimization model in the scenario 2 is displayed 231 in the equation 10.

232 $\operatorname{Minimize}(O F)=\sum_{t=1}^{T}\left(\frac{D_{t}-R_{t}}{D_{t}}\right)^{2}+\left(\frac{P H N_{t}-P H M_{t}}{P H N_{t}}\right)^{2}+\left(\frac{T H N_{t}-T H M_{t}}{T H N_{t}}\right)^{2}+\left(\frac{D H N_{t}-D H M_{t}}{D H N_{t}}\right)^{2}+P 1_{t}+P 2_{t}+P 3_{t}$

234 Particle swarm optimization (PSO) is one of the classic and widely used metaheuristic algorithms in the optimization models (Eberhart and Kennedy, 1995). Owing to previous successful application of the PSO, we utilized this optimization algorithm for the both optimization models. More details regarding

237 the methodology of this algorithm has been addressed in the literature (Eberhart and Kennedy, 1995). However, Figure 5 displays flowchart of this algorithm to find the best solution. 


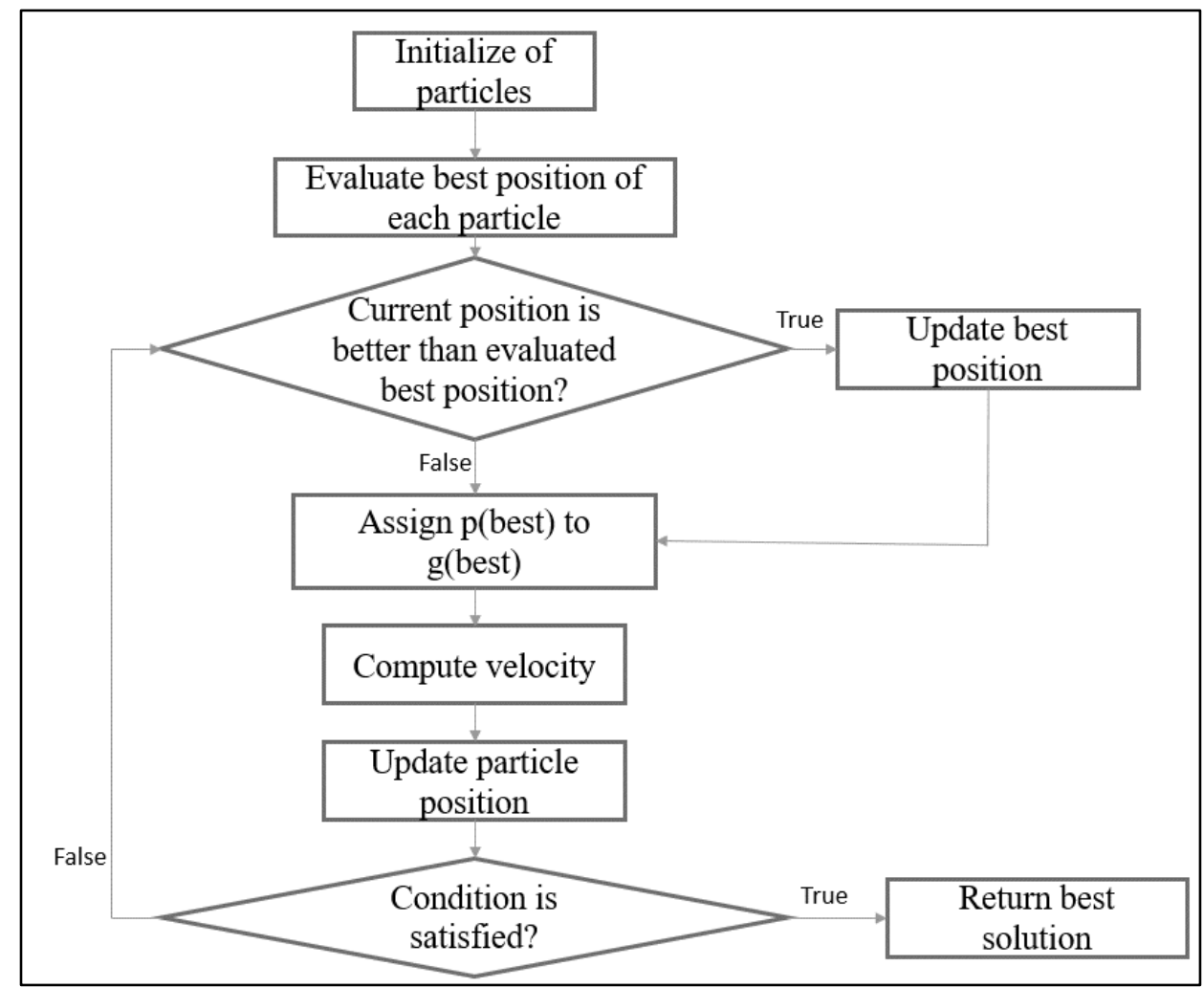

Figure 5-Particle swarm optimization (PSO) flowchart

\section{2-5-Measurement indices}

242 Different measurement indices were used in the proposed framework. Reliability index was considered to measure performance of the optimization model in the first and second scenarios in terms of water supply. This index has originally been developed by Hashimot et,al 1982 and improved by Ehteram et,al 2018. Equation 11 displays definition of this index. Storage loss is another aspect that should be measured. Vulnerability index has been developed by the Hashimoto et,al 1982 as well. We applied vulnerability index and root means square error (RMSE) to measure performance of the optimization models in terms of storage loss. Equation 12 and 13 displays definition of these indices regarding measurement of storage loss compared with optimal storage in the reservoir. Moreover, some indices are required to measure performance of the optimization models in terms of physical habitat loss,

251 thermal habitat and dissolved oxygen suitability loss. The Nash-Sutcliffe model efficiency coefficient (NSE) and RMSE were utilized in this regard as displayed in the following equations. It should be noted that optimal suitability is compared with natural condition at the downstream river reach. 
$254 R I_{\text {water demand }}=\frac{\sum_{t=1}^{T} R_{t}}{\sum_{t=1}^{T} D_{t}}$

255

$V I_{\text {storage }}=\operatorname{Max}_{t=1}^{T}\left(\frac{S_{\text {optimum }}-S_{t}}{S_{\text {optimum }}}\right)$

$256 \quad R M S E_{\text {Storage }}=\sqrt{\frac{\sum_{t=1}^{T}\left(S_{t}-S_{\text {Optimum }}\right)^{2}}{T}}$

$257 N S E_{\text {Physical habitat loss }}=1-\frac{\sum_{t=1}^{T}\left(\text { PHN }_{t}-P H M_{t}\right)^{2}}{\sum_{t=1}^{T}\left(P H N_{t}-P H N m\right)^{2}}$

$258 N S E_{\text {Themral habitat loss }}=1-\frac{\sum_{t=1}^{T}\left(T H N_{t}-T H M_{t}\right)^{2}}{\sum_{t=1}^{T}\left(T H N_{t}-T H N m\right)^{2}}$

$259 N S E_{\text {Dissolved oxygen habitat loss }}=1-\frac{\sum_{t=1}^{T}\left(D H N_{t}-D H M_{t}\right)^{2}}{\sum_{t=1}^{T}\left(D H N_{t}-D H N m\right)^{2}}$

$260 R M S E_{\text {Physical habitat loss }}=\sqrt{\frac{\sum_{t=1}^{T}\left(P H N_{t}-P H M_{t}\right)^{2}}{T}}$

$261 R M S E_{\text {Thermal habitat loss }}=\sqrt{\frac{\sum_{t=1}^{T}\left(T H N_{t}-T H M_{t}\right)^{2}}{T}}$

$262 R M S E_{\text {Dissolved habitat loss }}=\sqrt{\frac{\sum_{t=1}^{T}\left(D H N_{t}-D H M_{t}\right)^{2}}{T}}$

\section{2-6-Case study}

Tajan river is one of the most important rivers in the southern Caspian Sea basin in Iran where is a valuable habitat for many fish species. Owing to importance of the irrigation demand, Rajaei dam has been constructed at upstream of this river. Water demand is being pumped from the reservoir or before valuable downstream river habitats. In fact, release for environment is very low which raises challenges between regional water authority and regional department of environment. On the one hand, dam removal might be helpful to reduce severe environmental degradation at downstream. On the other hand, environmental optimization might decrease environmental degradation at downstream habitats. Owing to these ambiguities in the environmental management of this river basin, an integrated framework was necessary to assess dam removal and complexities of environmental management in this basin. Figure 6 displays land use, river network and location of the Rajaei reservoir in this basin. 


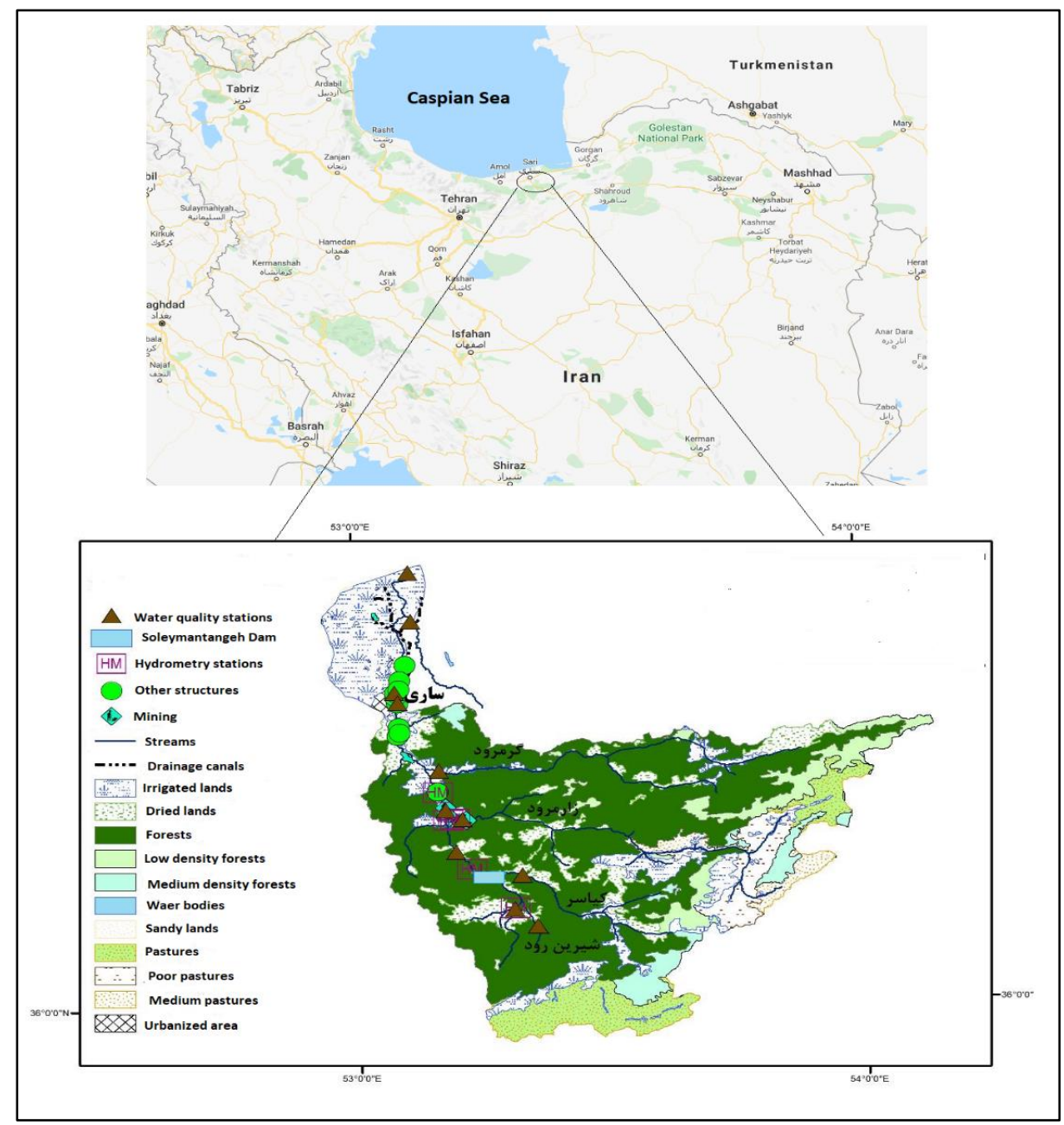

Figure 6- Land use, location of the Rajaei reservoir and river network map of Tajan basin

\section{3-Results and Discussion}

In the first step, it is required to present and discuss regarding results of the physical habitat simulation. Figure 7 displays developed fuzzy membership function for the physical habitats. Moreover, Table 3 displays developed fuzzy habitat rules for the target species that was the Brown trout. Figure 8 displays weighted useable curve (WUA) as the final output of the physical habitat simulation. This curve was utilized in the structure of the optimization model in the scenario 2. Fuzzy rules indicate that target species might be sensitive to flow velocity that seems logic. Because, high flow velocity increases energy consumption for the fish. In fact, fish swim to the upstream of the river for biological activities such as reproduction. Thus, they might consume energy to reach to the upstream. Other parameters such as depth and substrate might be effective as well. Deep water are a shelter for fish to conceal themselves from the predators. Moreover, substrate might be effective to enrich food sources for the fish. WUA 

8.
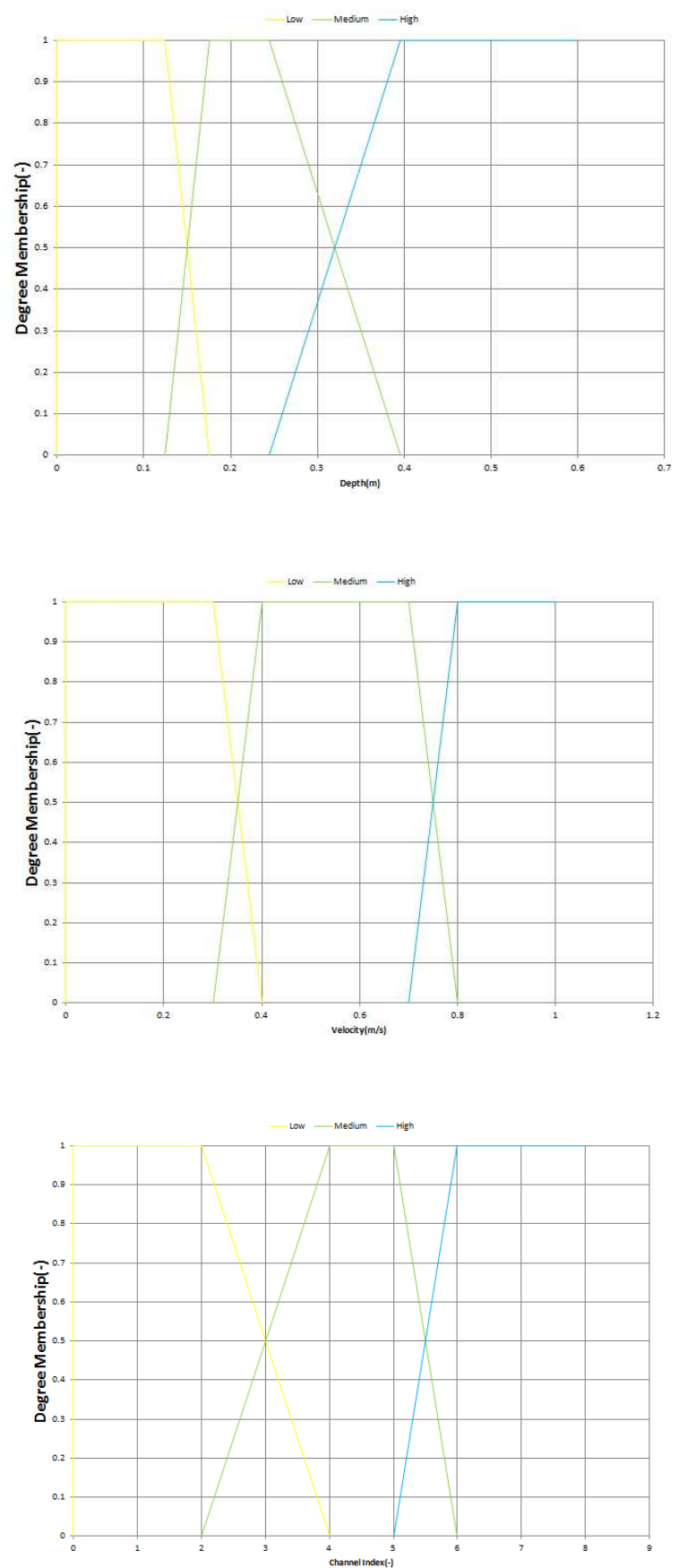


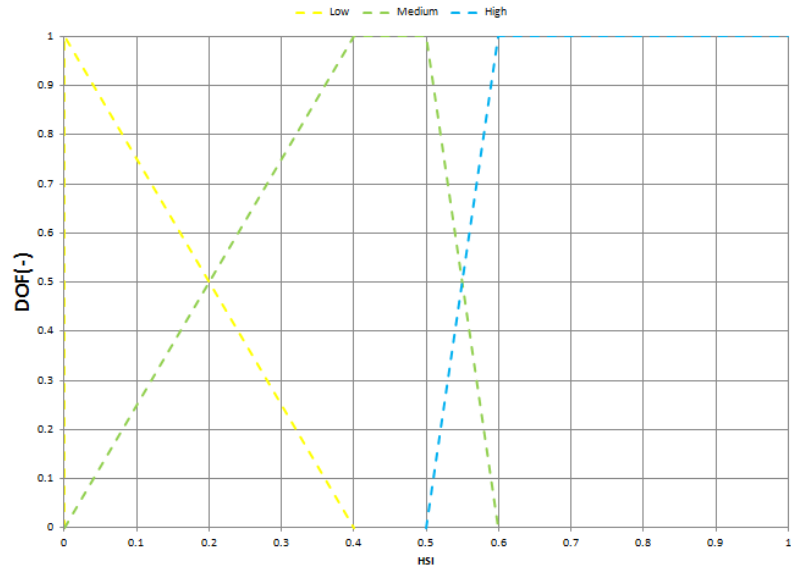

Figure 7- Developed membership functions for the physical habitat model

Table 3- Physical habitat fuzzy rules (L, M and $\mathrm{H}$ mean low, medium and high respectively)

\begin{tabular}{|c|c|c|c|c|}
\hline Rule Code & Depth & Velocity & Substrate & Habitat suitability \\
\hline$B R I$ & $M$ & 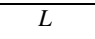 & $M$ & $M$ \\
\hline$B R 2$ & $H$ & $L$ & $M$ & $M$ \\
\hline$B R 3$ & $\begin{array}{l}L \\
\end{array}$ & $\begin{array}{l}L \\
\end{array}$ & $M$ & $\begin{array}{l}L \\
\end{array}$ \\
\hline$B R 4$ & $H$ & $M$ & $H$ & $H$ \\
\hline$B R 5$ & $L$ & $M$ & $H$ & $H$ \\
\hline BR6 & $M$ & $M$ & $H$ & $H$ \\
\hline$B R 7$ & $H$ & $H$ & $L$ & $L$ \\
\hline$B R 8$ & $M$ & $H$ & $L$ & $L$ \\
\hline$B R 9$ & 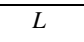 & $H$ & $L$ & $L$ \\
\hline BRI0 & $M$ & $M$ & $M$ & $M$ \\
\hline BRII & 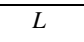 & $M$ & $M$ & $M$ \\
\hline BRI2 & $H$ & $M$ & $M$ & $M$ \\
\hline$B R 13$ & $M$ & $H$ & $M$ & $\begin{array}{l}L \\
\end{array}$ \\
\hline BR14 & $L$ & $H$ & $M$ & $L$ \\
\hline BRI5 & $H$ & $H$ & $M$ & $L$ \\
\hline BR16 & $L$ & $L$ & $L$ & $L$ \\
\hline BR17 & $M$ & $L$ & $L$ & $L$ \\
\hline BR18 & $H$ & $L$ & $L$ & $M$ \\
\hline BRI9 & $L$ & $\begin{array}{l}L \\
\end{array}$ & H & $M$ \\
\hline BR20 & $M$ & $L$ & $H$ & $M$ \\
\hline BR21 & $H$ & $L$ & $H$ & $H$ \\
\hline$B R 22$ & $M$ & $M$ & $\bar{L}$ & $H$ \\
\hline$B R 23$ & $H$ & $M$ & $L$ & $H$ \\
\hline
\end{tabular}




\begin{tabular}{|c|c|c|c|c|}
\hline BR24 & $L$ & $M$ & $L$ & $M$ \\
\hline$B R 25$ & $L$ & $H$ & $H$ & $L$ \\
\hline$B R 26$ & $M$ & $H$ & $H$ & $L$ \\
\hline$B R 27$ & $H$ & $H$ & $H$ & $L$ \\
\hline
\end{tabular}

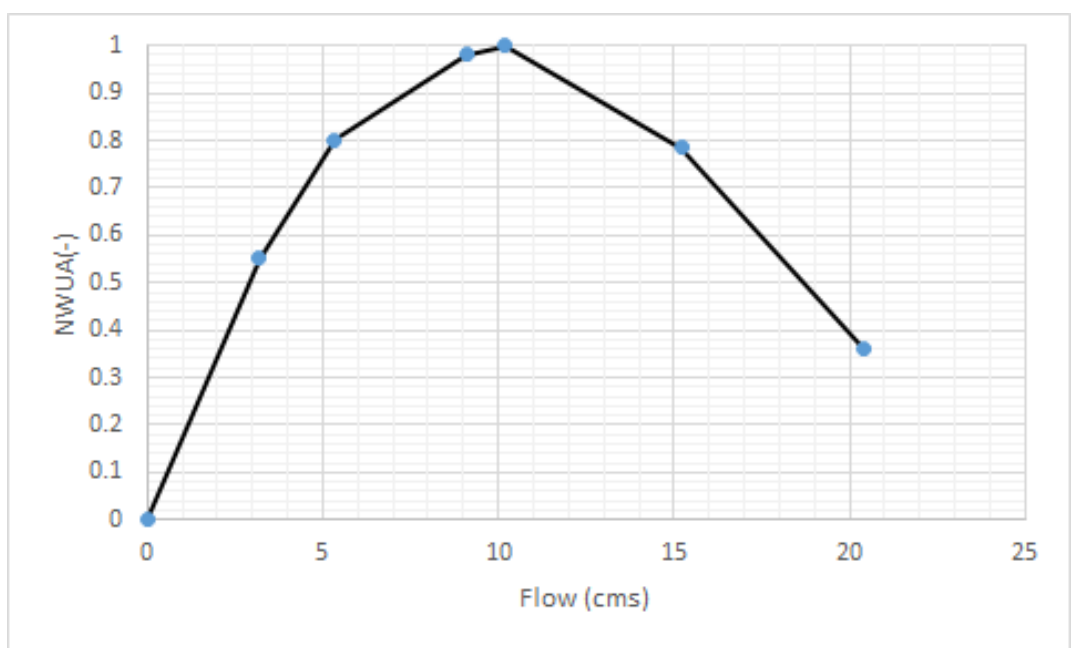

Figure 8- Normalized weighted useable area curve (NWUA)

In the second step, validation result of the thermal data driven model should be presented. Figure 9 displays validation results of the thermal habitat tension model in which NSE was computed. NSE is 0.95 that means model is very robust regarding simulation of the stream temperature. According to the literature, if NSE is more than 0.5 , model might be very robust in terms of predictive skills. However, NSE more than zero might be acceptable. Moreover, Figure 10 displays validation results of the dissolved oxygen model. NSE is 0.04 in this model. It seems that DO model is not very robust for simulation. However, it is acceptable. It should be noted that modelling of DO might be complex due to impact of water pollutants and other factors. Hence, performance of developed model might be defensible based on these complexities to simulate dissolved oxygen in the stream. Our case study indicated that dissolved oxygen modelling should be considered as one of the sources of uncertainty in the present framework. However, it might be different case by case and the proposed data driven model might be very robust in other cases in which complexities are not considerable regarding water quality issues. 


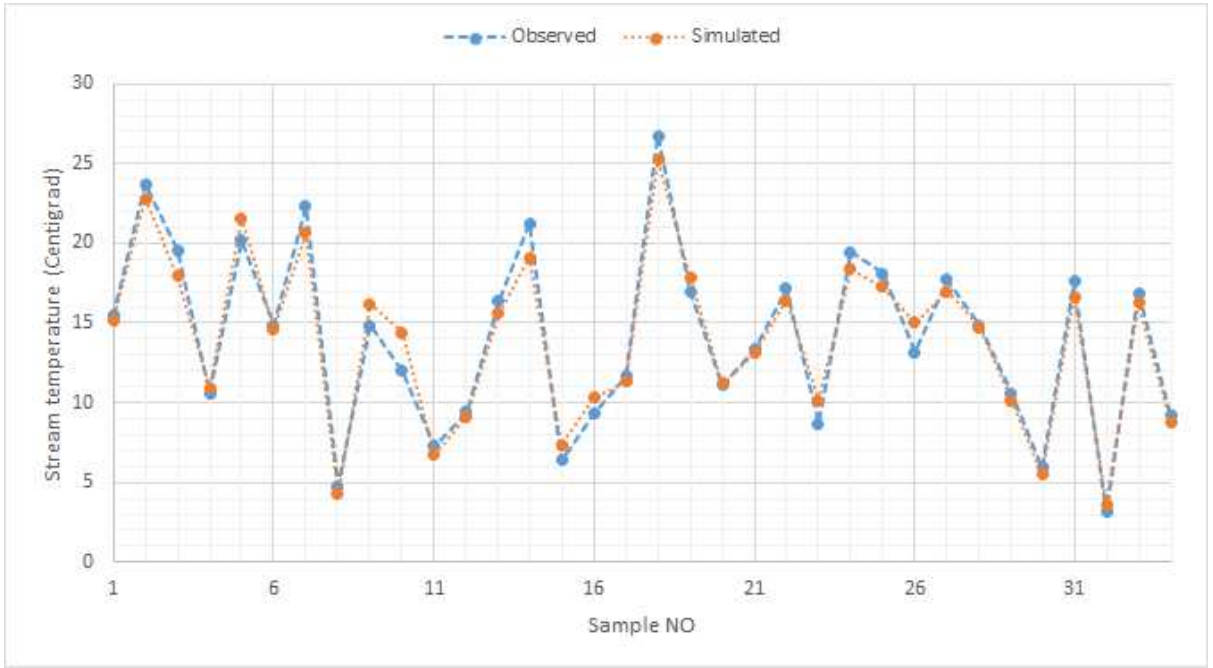

Figure 9- Validation results of the data driven stream temperature model

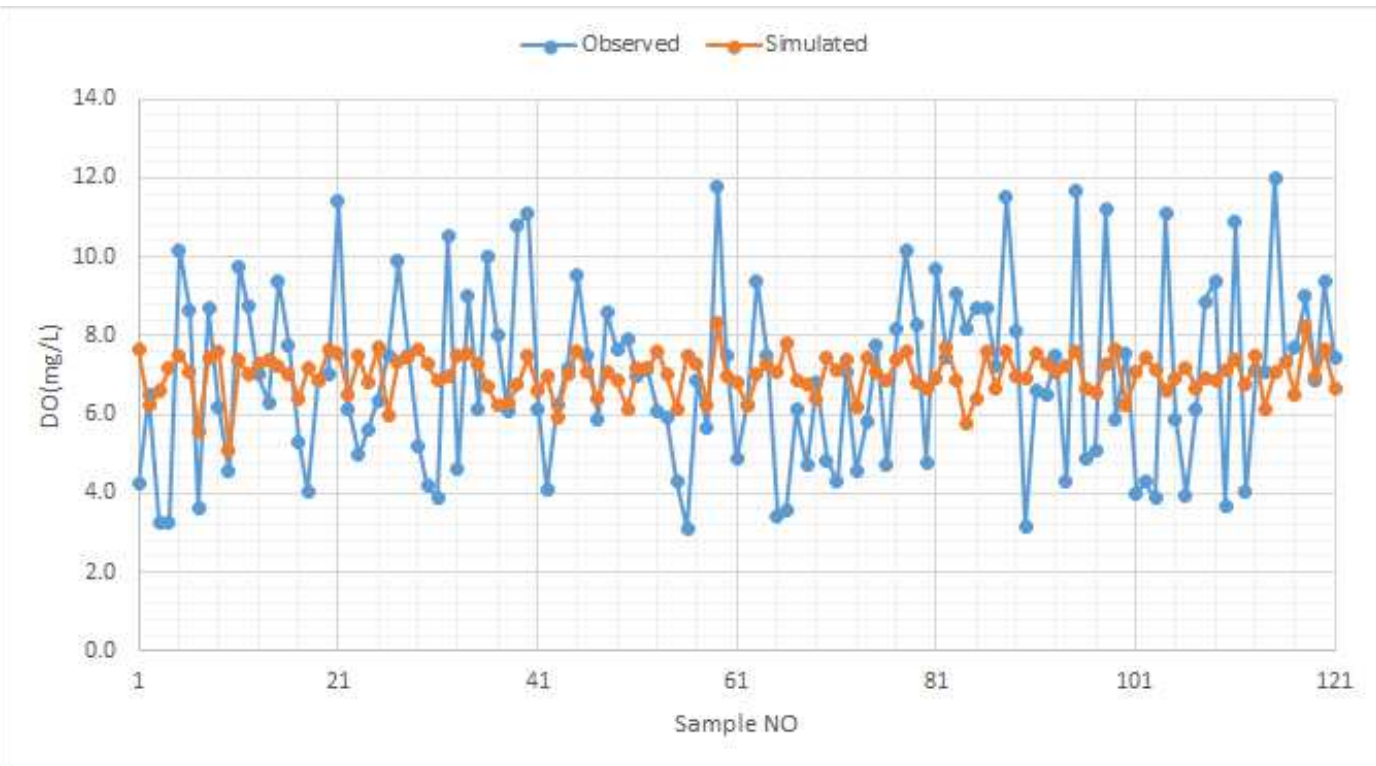

Figure 10- Validation results of the data driven dissolved oxygen model

316 It should be noted that based on undocumented studies by the department of environment two linear

317 regression models were developed at upstream of the reservoir. Owing to absence of reservoir impact

318 and other pollutants, water temperature and concentration of dissolved oxygen were depended on the

319 air temperature and water temperature respectively. These equations were used in the environmental assessment for the natural flow. Equation 20 and 21 displays these regression models. High dissolved oxygen concentration is the main feature for the natural flow in this river basin. 
324 In the third step, results of the optimization should be presented and discussed. We selected a 72 months 325 period as the simulation period in the present study that was a challenging period for the reservoir and 326 river basin due to low inflows of the reservoir in some months. Figure 11 displays inflow of the reservoir, optimal release for water demand and maximum water demand. It should be noted that maximum water demand was considered based on recommendations by the regional water authority in the case study. In fact, this is maximum water demand for the river basin that might be supplied by the surface and ground water resources. However, it was considered to supply water demand by the reservoir as much as possible. Owing to lower reservoir inflow in the three first years of the simulation, supplied demand is much lower than other years. Results indicate that reservoir might have significant role to regulate release for demand in the simulated period. Because, natural flow is high in some months in which requested water demand is low. In other words, optimization model in the scenario 1 demonstrates that reservoir might be very effective for management of the irrigation demand in the river basin. However, using other options such as storage in the agricultural pools in the farms might be an option if dam is removed. Thus, it should be analysed how dam removal might be helpful to restore river habitat that would be discussed in the further steps. Another important result of the optimization in the scenario 1 is storage time series in the simulated period. Figure 12 displays storage in the reservoir in the simulated period. Minimum operational storage, maximum storage and optimal storage are displayed in this figure as well. 


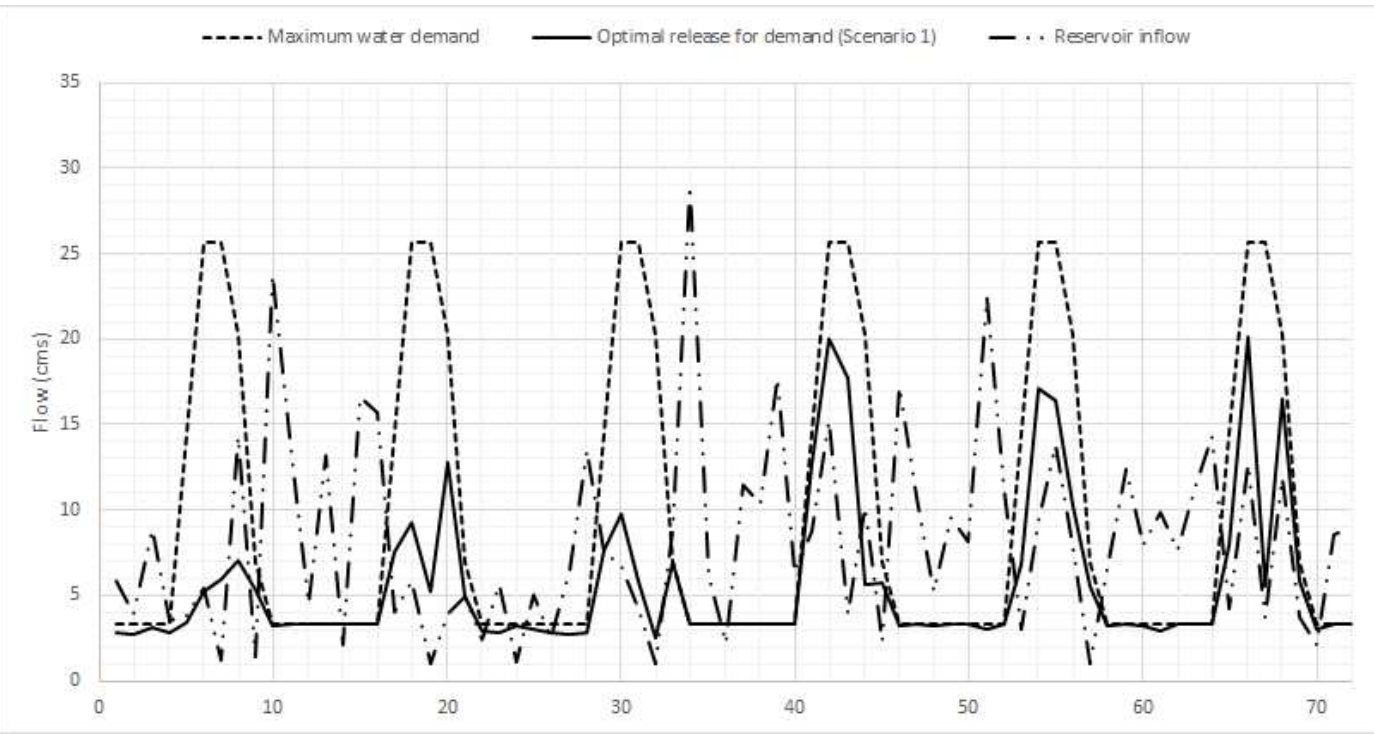

Figure 11- Reservoir inflow, release for demand in the scenario 1 and maximum water demand in the simulated period

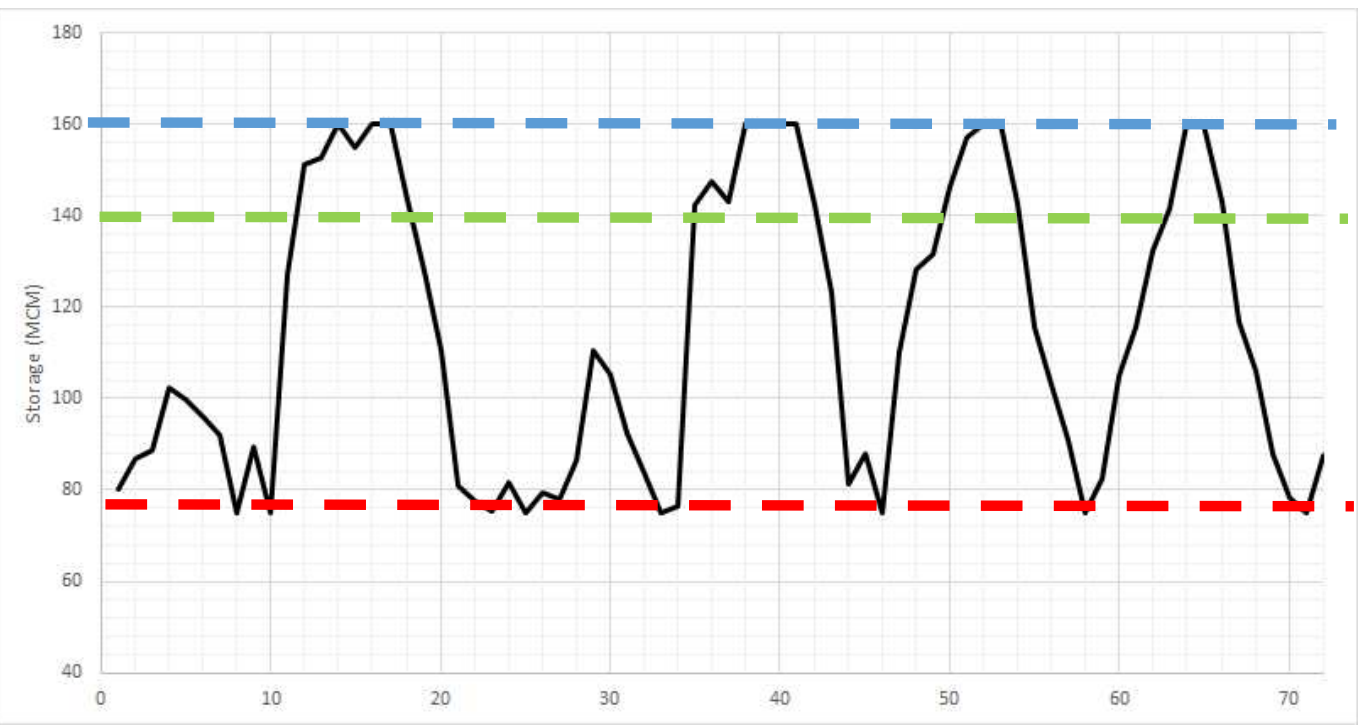

Figure 12- Storage of the reservoir in the simulated period for the optimization model in the scenario 1

The performance of the penalty functions including minimum operational storage and maximum storage is robust. Because, storage time series indicates that optimization model is able to keep the storage between minimum operational storage and maximum storage. Thus, general performance of optimization model in the scenario 1 in terms of storage is acceptable. However, analysis of the storage 
loss needs related measurement indices that will be discussed. Figure 13 displays release for demand, reservoir inflow and maximum demand in the scenario 2. It seems that considering environmental aspects with a focus on environmental flow in the optimization model changes supplied demand especially in the first years of the simulated period due to low inflow of the reservoir. Hence, low supplied flow in some time steps might be a challenge for using the proposed optimization framework in the scenario 2. It should be noted further analysis on this issue is depended on the challenges and certain issues of each case study that means it might be different case by case. In our case study, release for demand in each time step was not very effective. In contrast, total release in the simulated period was important. Thus, using reliability index seems logic in this case. However, engineers might use other indices in the other case studies. More water is supplied in the third, fourth and fifth year of the simulated period. Figure 14 displays storage time series in the scenario 2 that indicates changing the storage in the reservoir is considerable compared with the scenario 1. Less storage in some simulated time steps is obvious. Hence, storage loss might be increased in the optimal release for environment and demand. However, accurate analysis needs using measurement indices.

Moreover, environmental results should be presented and discussed in the Scenario 2. Figure 15 displays normalized weighted useable area (NWUA) time series in the simulated period. WUA was normalized by maximum WUA to present in the form of the NWUA. Because, it is more fathomable for interpretation of the results in the further applications. There is a significant change compared with natural flow. Generally, it seems that using optimal reservoir operation considering environmental aspects is not able to increase useable area as much as natural flow. It might corroborate the opinion of the environmental advocators to remove dam. Reducing NWUA is a serious concern for some time steps in the simulated period. It should be noted that in some time steps, NWUA in the scenario 2 is more than natural flow. In fact, optimal operation might be able to increase suitability of the physical habitats compared with natural flow as a positive aspect of the dam. However, it was occurred for rare time steps in the case study.

Thermal tension is another aspect that should be discussed in the present study. Figure 16 displays thermal tension time series in the simulated period that compares thermal tension in the natural flow 
and optimal release for the environment and demand by the reservoir. Results indicate that output of the thermal tension might be complex. Because, thermal tension is considerably reduced in some time steps. However, it is increased in other time step. Hence, reservoir might have positive and negative effect in a simulated period. In fact, reservoir might be an applicable tool to control thermal tension at downstream habitats in some cases. Results are not interpretable based on thermal tension time series observably.

Dissolved oxygen tension is another aspect in the environmental analysis of the scenario 2 as displayed in the figure 17. Dissolved oxygen tension in the natural flow is close to zero in all of the time steps. However, optimal release for environment and demand indicates that optimization model is not able to minimize differences in many time steps. However, it is undeniable that performance of the optimization model is perfect in some time steps. A point should be noted regarding dissolved oxygen model. As discussed, validation of the DO model demonstrated that model is not very reliable in the case study. However, general trend of the results was acceptable. High uncertainty of the model might reduce reliability of the optimization model in terms of DO optimization. It should be noted that considering this uncertainty is essential for final application of the results. However, significant difference between simulated tension in the scenario 2 and natural flow in some steps indicates that results of the optimization model might be reliable.

As mentioned, full discussion on the results and making a decision in the case study need using measurement indices. Figure 18 displays reliability index of the water demand in the both scenarios. Decreasing reliability of water supply is remarkable in the case study. In fact, reliability is changed $15 \%$ approximately that demonstrates economic benefits from the reservoir might reduce considerably due to using an optimal operation considering environmental aspects. Moreover, figure 19 displays measurement indices for the storage loss including RMSE and VI. Results demonstrate that changing storage loss in the scenario 2 compared with scenario 1 is not tangible. Thus, using and optimal reservoir operation considering environmental aspects in the structure of the optimization model might not weaken storage benefits in the reservoir of the case study. 
Table 4 displays NSE and RMSE for three environmental aspects in the proposed framework including

407 physical habitat loss, thermal habitat loss and dissolved oxygen loss. It should be noted that only positive difference between simulation and optimization in the scenario 2 and natural flow was considered to compute indices. In other words, if physical habitat loss is more than natural flow in the scenario 2, it will be considered equal to NWUA in the natural flow. This consideration was applied regarding thermal tension and dissolved oxygen tension as well. NSE for physical habitat loss is -3.43 that indicates optimization model is not able to provide physical habitat loss as suitable as natural flow. Moreover, RMSE for physical habitat loss is 0.41 that demonstrates considerable difference between suitability of physical habitats in two statuses. Moreover, NSE for thermal tension shows that performance of the optimization model is acceptable in terms of thermal tension. However, RMSE is considerable. Because, $29 \%$ of the thermal tension might make habitat unsuitable especially for the sensitive species such as the Brown trout. Furthermore, performance of the optimization model is not defensible in terms of the DO tension based on computed indices.

Finally, it is possible to judge on the feasibility and advantages of the dam removal project in the case study based on all of the results. It seems that optimal operation considering environmental flow is not other options in the case study for supply of water such as storage in the pools of the farms should come into picture, if protecting environmental values at downstream is aimed. In fact, dam removal seems reservoirs should be considered in the habitat restoration projects as well. proposed framework is high computational complexities. This term might be defined as required time 
and memory for using an algorithm in the optimization. Owing to using ANFIS based model in the

434

435

436

437

438

439

440

441

442

structure of the optimization model, computational complexities is considerable. Thus, using this framework for long-term period or numerous simulations might need powerful computers and it might be time consuming. Moreover, we considered water demand in the proposed framework based on the case study. It is needed to consider other aspects such as hydropower in the future studies. Furthermore, it is essential to consider uncertainties of the ANFIS based model for further applications of the results.

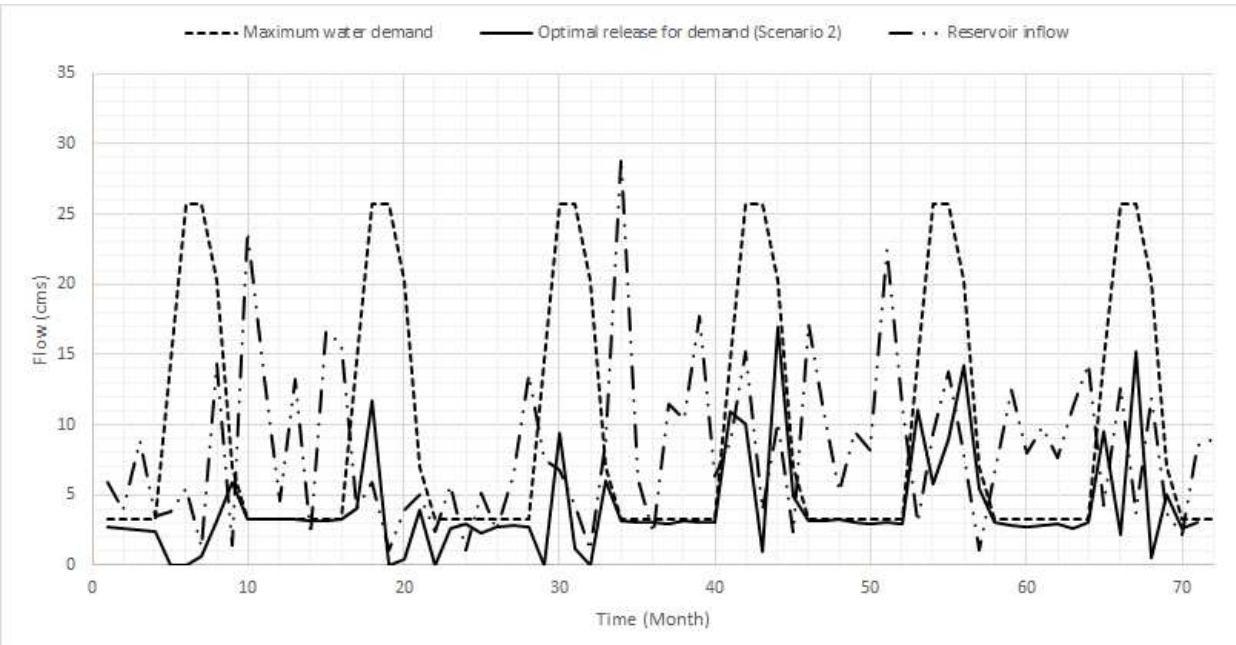

Figure 13- Reservoir inflow, release for demand in the scenario 2 and maximum water demand in the simulated period

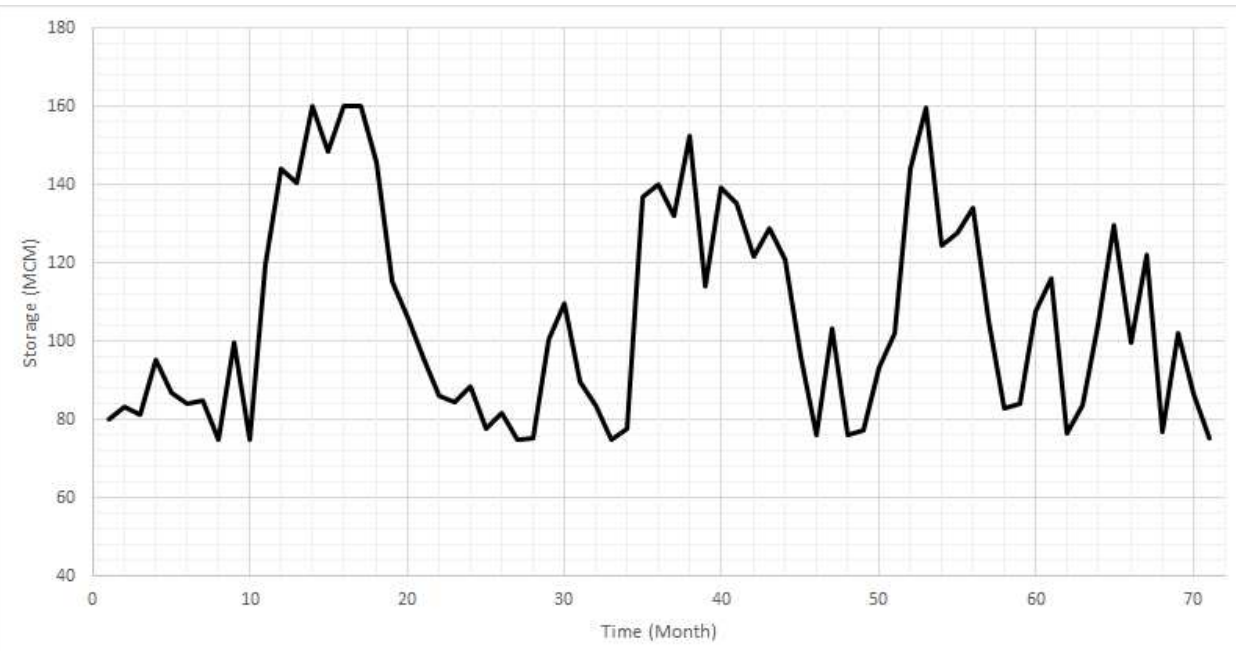




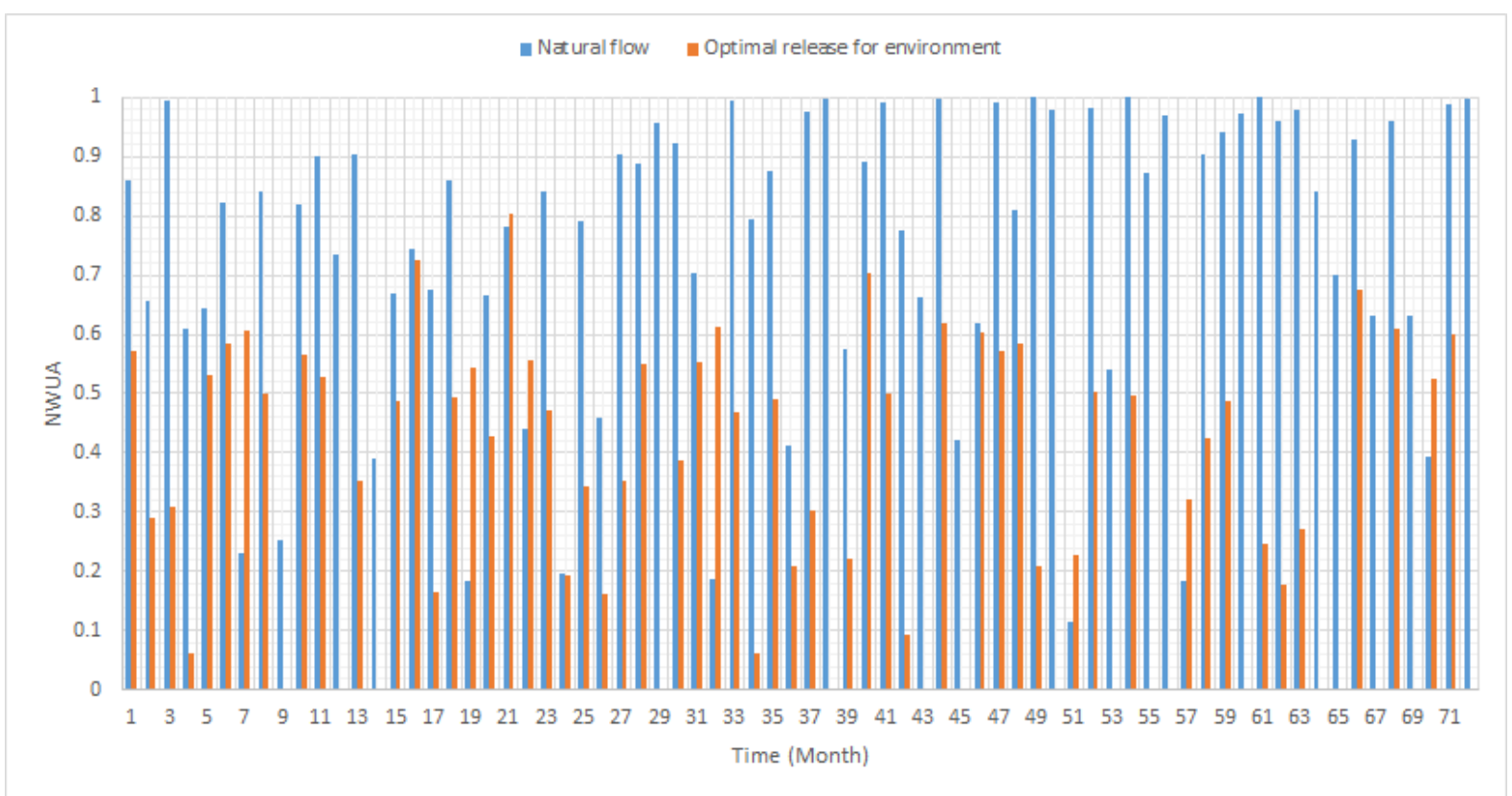

449

Figure 15- NWUA time series in the simulated period for the optimization model in the scenario 2

450

451 


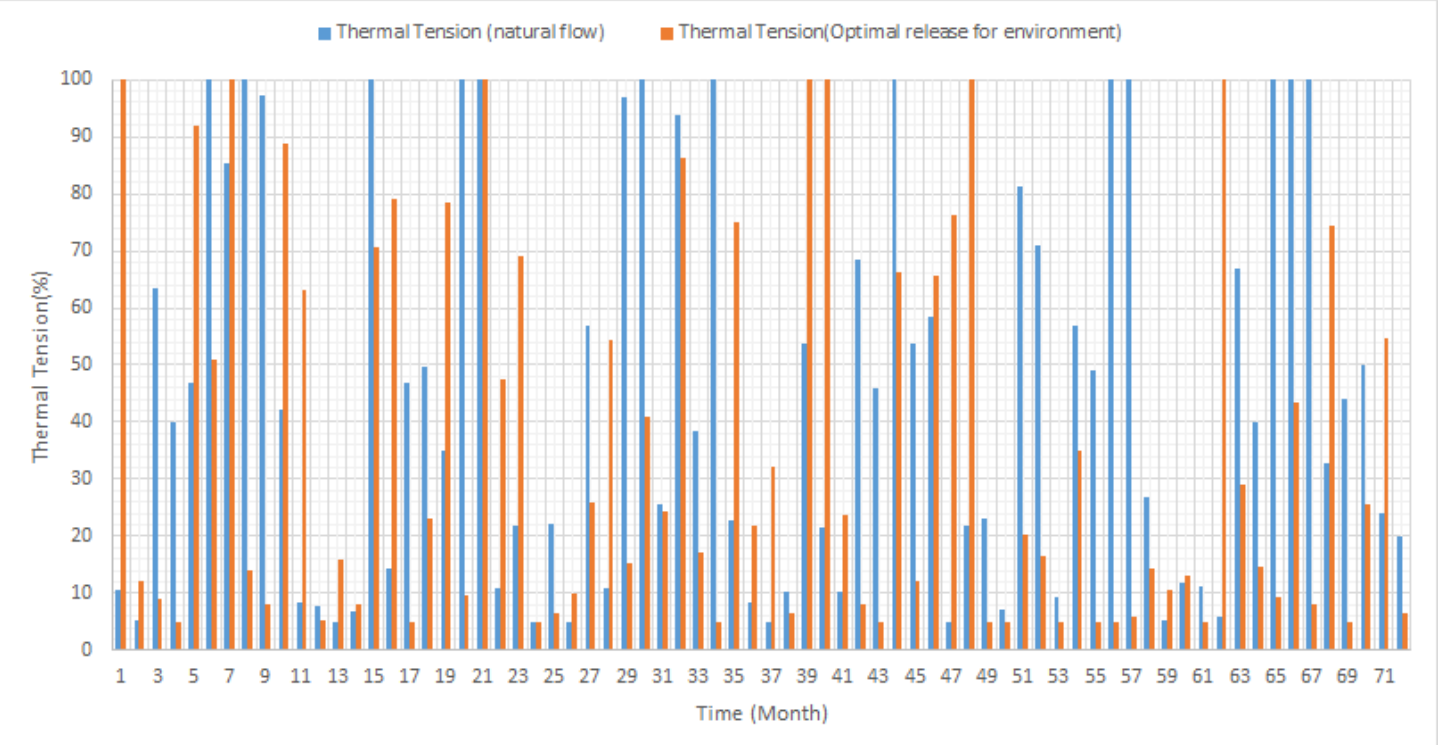

453

454

455

456

457

Figure 17- DO tension time series in the simulated period for the optimization model in the scenario 2

Figure 16- Thermal tension time series in the simulated period for the optimization model in the scenario 2

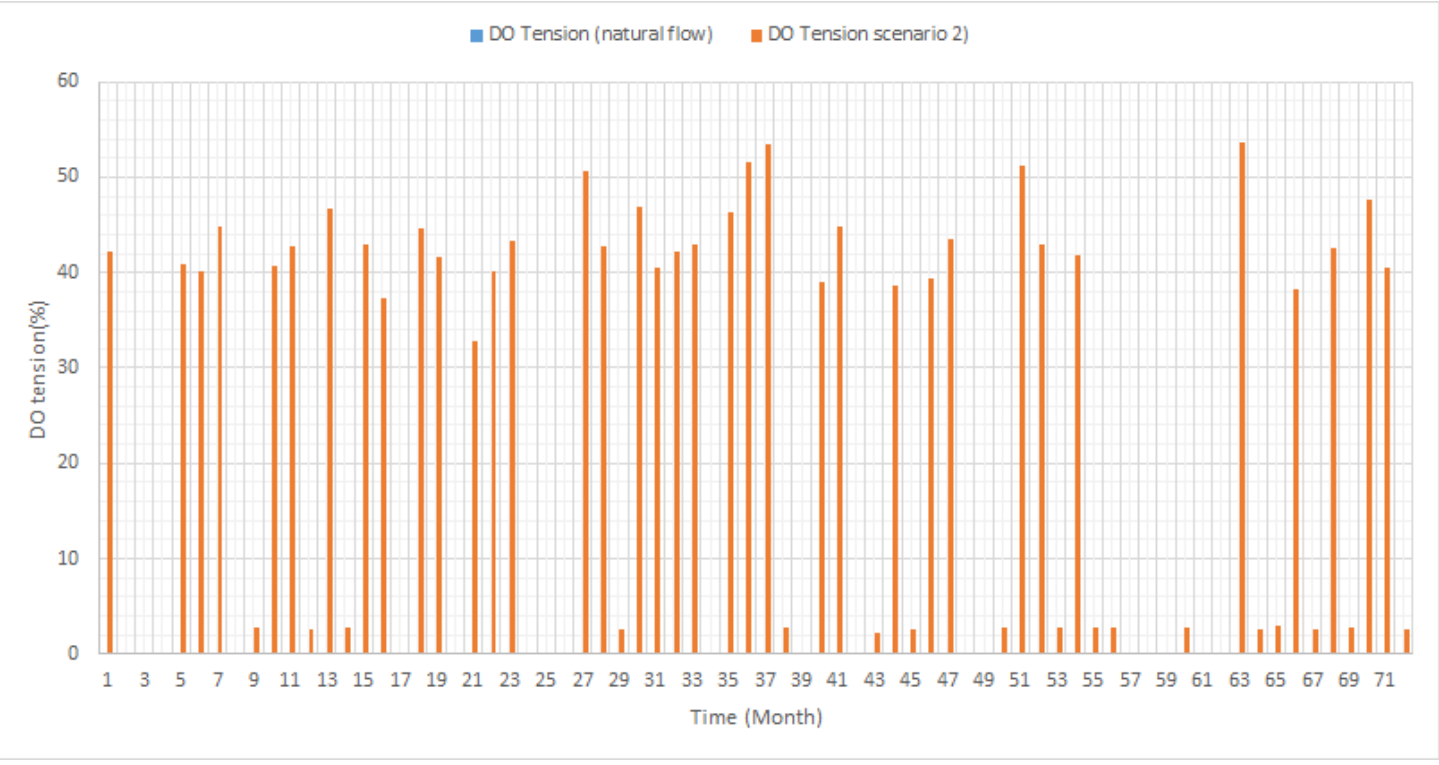

459

460 


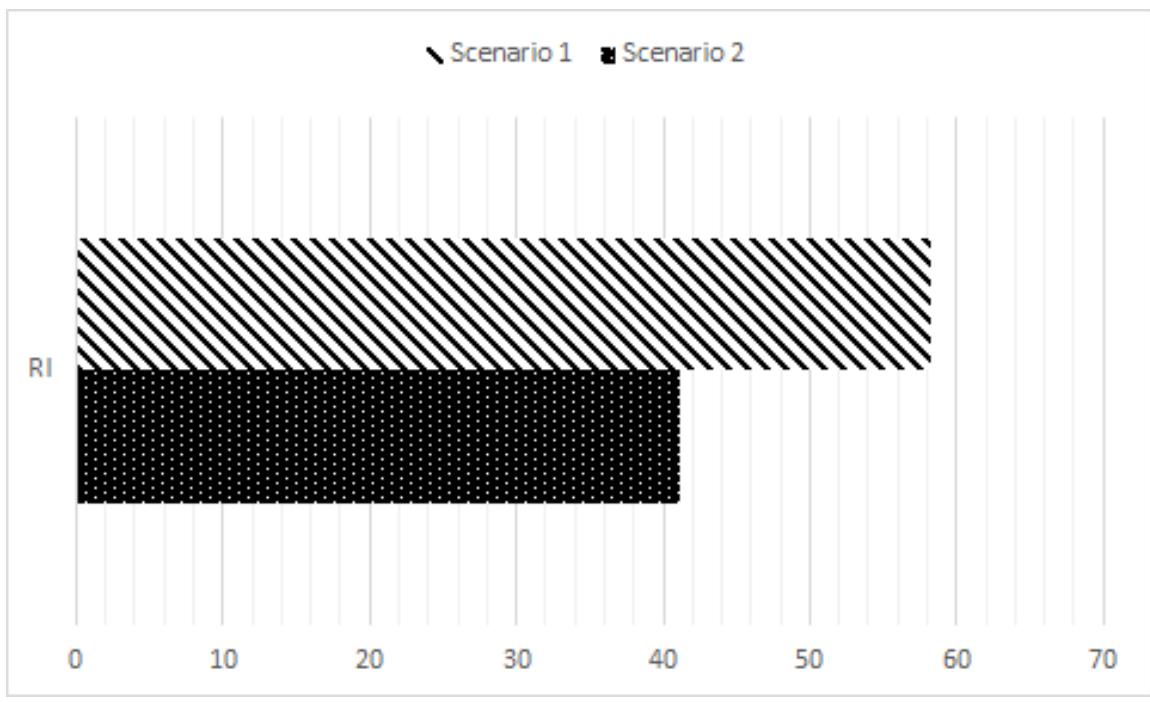

462

Figure 18- Reliability index for water supply

463

464

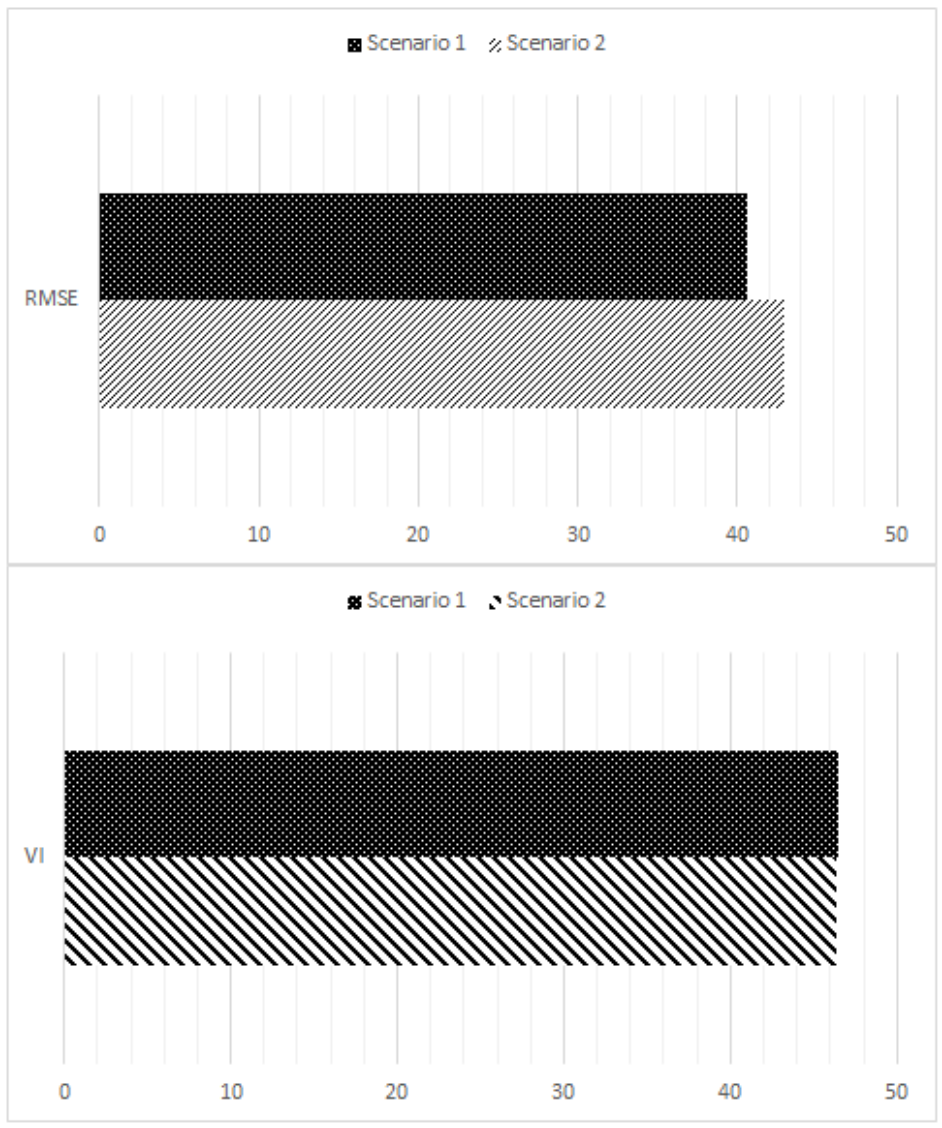

Figure 19- Measurement indices for storage loss 


\begin{tabular}{|l|c|c|c|}
\hline & $\begin{array}{c}\text { Physical } \\
\text { habitat } \\
\text { loss }\end{array}$ & $\begin{array}{c}\text { Thermal } \\
\text { habitat loss }\end{array}$ & Dissolved \\
& oxygen loss \\
\hline NSE & -3.43 & 0.30 & $0>>$ \\
\hline RMSE & 0.41 & 29.16 & 30.66 \\
\hline
\end{tabular}

469

470

\section{4-Conclusion}

Present study proposed a novel framework to simulate environmental aspects of the dam removal for making decision on the necessities and advantages of the dam removal projects. Two scenarios were considered including a conventional reservoir operation optimization and optimal operation considering environmental aspects in the structure of the optimization model. First scenario and second scenario were compared in terms of the water supply and storage losses. Moreover, the outputs of the scenario 2 was compared with the natural flow in terms of physical habitat loss, thermal habitat loss and dissolved oxygen habitat loss by applying NSE and RMSE as measurement indices. Based on the results in the case study, reliability of water supply was remarkably reduced in the scenario 2 that demonstrates optimal release considering environmental issues might be challenging for the water demand management in the river basin. Moreover, optimal release considering environmental aspects is not able to reduce tensions and losses as suitable as natural flow. Thus, dam removal is recommendable in terms of environmental suitability at downstream aquatics habitats.

\section{5-Declarations}

\section{Ethical Approval}

Not applicable

\section{Consent to Participate}


$489 \quad$ Not applicable

490 Authors Contributions

491 MS is responsible for writing of the manuscript and related programming and calculations. AA is

492 responsible for field studies and reviewing the research work

$493 \quad$ Funding

494 Not applicable

\section{Competing Interests}

496 Not applicable

\section{Availability of data and materials}

498

499

500

501

502

503

504

505

506

507

508

509

Some or all data and materials that support the findings of this study are available from the corresponding author upon reasonable request.

\section{References}

Afshar, A., Haddad, O.B., Mariño, M.A. and Adams, B.J., 2007. Honey-bee mating optimization (HBMO) algorithm for optimal reservoir operation. Journal of the Franklin Institute, 344(5), pp.452462.

Afshar, A., Shafii, M. and Haddad, O.B., 2011. Optimizing multi-reservoir operation rules: an improved HBMO approach. Journal of Hydroinformatics, 13(1), pp.121-139.

Agarwal, M. and Gupta, R., 2005. Penalty function approach in heuristic algorithms for constrained redundancy reliability optimization. IEEE Transactions on Reliability, 54(3), pp.549-558.

Ahmad, A., El-Shafie, A., Razali, S.F.M. and Mohamad, Z.S., 2014. Reservoir optimization in water resources: a review. Water resources management, 28(11), pp.3391-3405. 
510 Ahmadi-Nedushan, B., St-Hilaire, A., Bérubé, M., Robichaud, É., Thiémonge, N. and Bobée, B., 2006.

511 A review of statistical methods for the evaluation of aquatic habitat suitability for instream flow

512 assessment. River Research and Applications, 22(5), pp.503-523.

513 Altinbilek, D., 2002. The role of dams in development. Water Science and Technology, 45(8), pp.169-

514180.

515 Amirkhani, M., Bozorg-Haddad, O., Fallah-Mehdipour, E. and Loáiciga, H.A., 2016. Multiobjective 516 reservoir operation for water quality optimization. Journal of Irrigation and Drainage Engineering, 517 142(12), p.04016065.

518 Arunkumar, R. and Jothiprakash, V., 2012. Optimal reservoir operation for hydropower generation 519 using non-linear programming model. Journal of The Institution of Engineers (India): Series A, 93(2), 520 pp.111-120.

521 Awan, J.A. and Bae, D.H., 2014. Improving ANFIS based model for long-term dam inflow prediction by incorporating monthly rainfall forecasts. Water resources management, 28(5), pp.1185-1199. Bartholow, J.M., 2000. The stream segment and stream network temperature models: A self-study course (No. 99-112). US Geological Survey.

Bednarek, A.T., 2001. Undamming rivers: a review of the ecological impacts of dam removal. Environmental management, 27(6), pp.803-814.

527 Chatterjee, S., Sarkar, S., Dey, N., Ashour, A.S., Sen, S. and Hassanien, A.E., 2017. Application of cuckoo search in water quality prediction using artificial neural network. International Journal of 529 Computational Intelligence Studies, 6(2-3), pp.229-244.

530 Devi, P.A., Padmavathy, P., Aanand, S. and Aruljothi, K., 2017. Review on water quality parameters 531 in freshwater cage fish culture. International Journal of Applied Research, 3(5), pp.114-120.

532 Dumitru, C. and Maria, V., 2013. Advantages and Disadvantages of Using Neural Networks for 533 Predictions. Ovidius University Annals, Series Economic Sciences, 13(1).

534 Eberhart, R. and Kennedy, J., 1995, November. Particle swarm optimization. In Proceedings of the IEEE international conference on neural networks (Vol. 4, pp. 1942-1948). Citeseer. 
537 operation by a new evolutionary algorithm: Kidney algorithm. Water resources management, 32(14), pp.4681-4706.

Eklöv, A.G., Greenberg, L.A., Brönmark, C., Larsson, P. and Berglund, O., 1999. Influence of water quality, habitat and species richness on brown trout populations. Journal of Fish Biology, 54(1), pp.3343.

Foley, M.M., Bellmore, J.R., O'Connor, J.E., Duda, J.J., East, A.E., Grant, G.E., Anderson, C.W., Bountry, J.A., Collins, M.J., Connolly, P.J. and Craig, L.S., 2017. Dam removal: Listening in. Water Resources Research, 53(7), pp.5229-5246.

Gupta, H.V., Kling, H., Yilmaz, K.K. and Martinez, G.F., 2009. Decomposition of the mean squared error and NSE performance criteria: Implications for improving hydrological modelling. Journal of hydrology, 377(1-2), pp.80-91.

Harby, A., Baptist, M., Dunbar, M.J. and Schmutz, S., 2004. State-of-the-art in data sampling, modelling analysis and applications of river habitat modelling: COST action 626 report (Doctoral dissertation, Univerza v Ljubljani, Naravoslovnotehniška fakulteta).

Hashimoto, T., Stedinger, J.R. and Loucks, D.P., 1982. Reliability, resiliency, and vulnerability criteria for water resource system performance evaluation. Water resources research, 18(1), pp.14-20. Jahandideh-Tehrani, M., Bozorg-Haddad, O. and Loáiciga, H.A., 2019. Application of non-animalinspired evolutionary algorithms to reservoir operation: an overview. Environmental monitoring and assessment, 191(7), pp.1-21. Jang, J.S., 1993. ANFIS: adaptive-network-based fuzzy inference system. IEEE transactions on systems, man, and cybernetics, 23(3), pp.665-685. Jowett, I.G. and Duncan, M.J., 2012. Effectiveness of 1D and 2D hydraulic models for instream habitat analysis in a braided river. Ecological Engineering, 48, pp.92-100.

Major, J.J., East, A.E., O’Connor, J.E., Grant, G.E., Wilcox, A.C., Magirl, C.S., Collins, M.J. and perspective. Gravel-bed rivers, 10(9781118971437), pp.355-383. 

637.

Reis, L.F.R., Bessler, F.T., Walters, G.A. and Savic, D., 2006. Water supply reservoir operation by combined genetic algorithm-linear programming (GA-LP) approach. Water resources management, 20(2), pp.227-255.

Sedighkia, M., Abdoli, A., Ayyoubzadeh, S.A. and Ahmadi, A., 2019. Modelling of thermal habitat loss of brown trout (Salmo trutta) due to the impact of climate warming. Ecohydrology \& Hydrobiology, 19(1), pp.167-177.

Sedighkia, M., Ayyoubzadeh, S.A. and Haji Esmaeili, M., 2017. Habitat simulation technique as a powerful tool for instream flow needs assessment and river ecosystem management. Environmental Energy and Economic Research, 1(2), pp.171-182.

576 Tahmiscioğlu, M.S., Anul, N., Ekmekçi, F. and Durmuş, N., 2007, March. Positive and negative 577 impacts of dams on the environment. In International Congress on River Basin Management (pp. 2224).

Vismara, R., Azzellino, A., Bosi, R., Crosa, G. and Gentili, G., 2001. Habitat suitability curves for brown trout (Salmo trutta fario L.) in the River Adda, Northern Italy: comparing univariate and multivariate approaches. Regulated Rivers: Research \& Management: An International Journal Devoted to River Research and Management, 17(1), pp.37-50.

Waddle, T., 2001. PHABSIM for Windows user's manual and exercises (No. 2001-340). Canyon based on physical habitat and population models. Mathematical biosciences, 298, pp.91-104. 
Figures

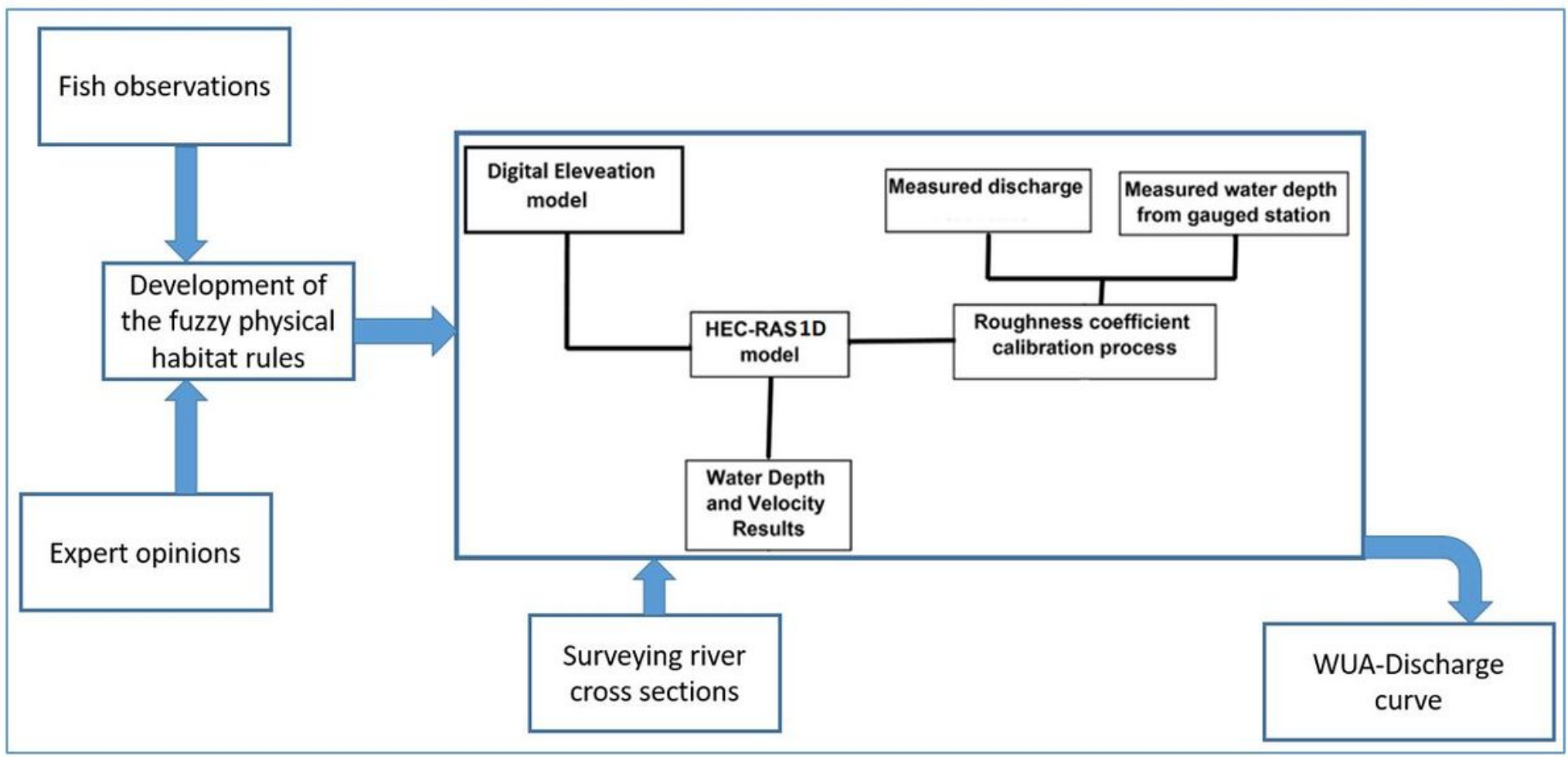

\section{Figure 1}

flowchart of the physical habitat simulation in the proposed framework

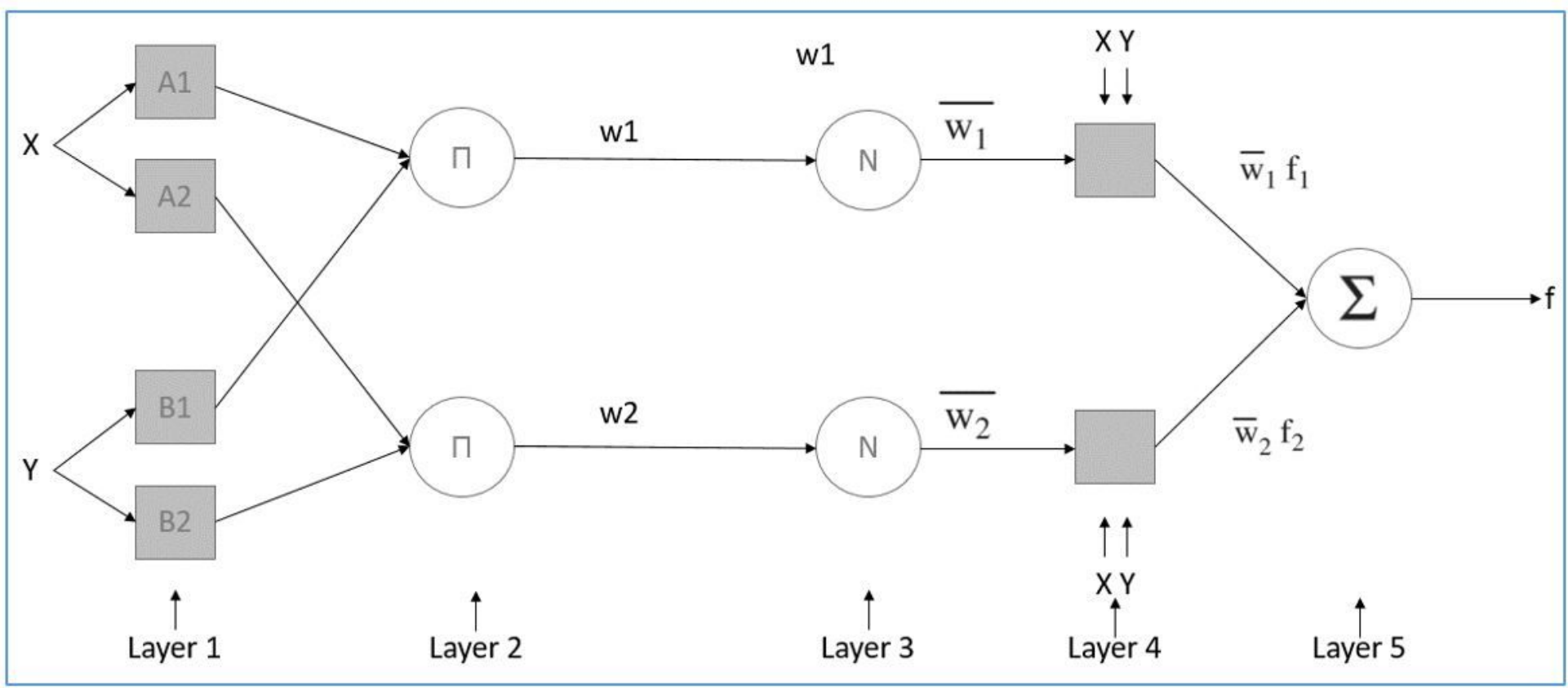

Figure 2

Simple structure of ANFIS based data driven model 


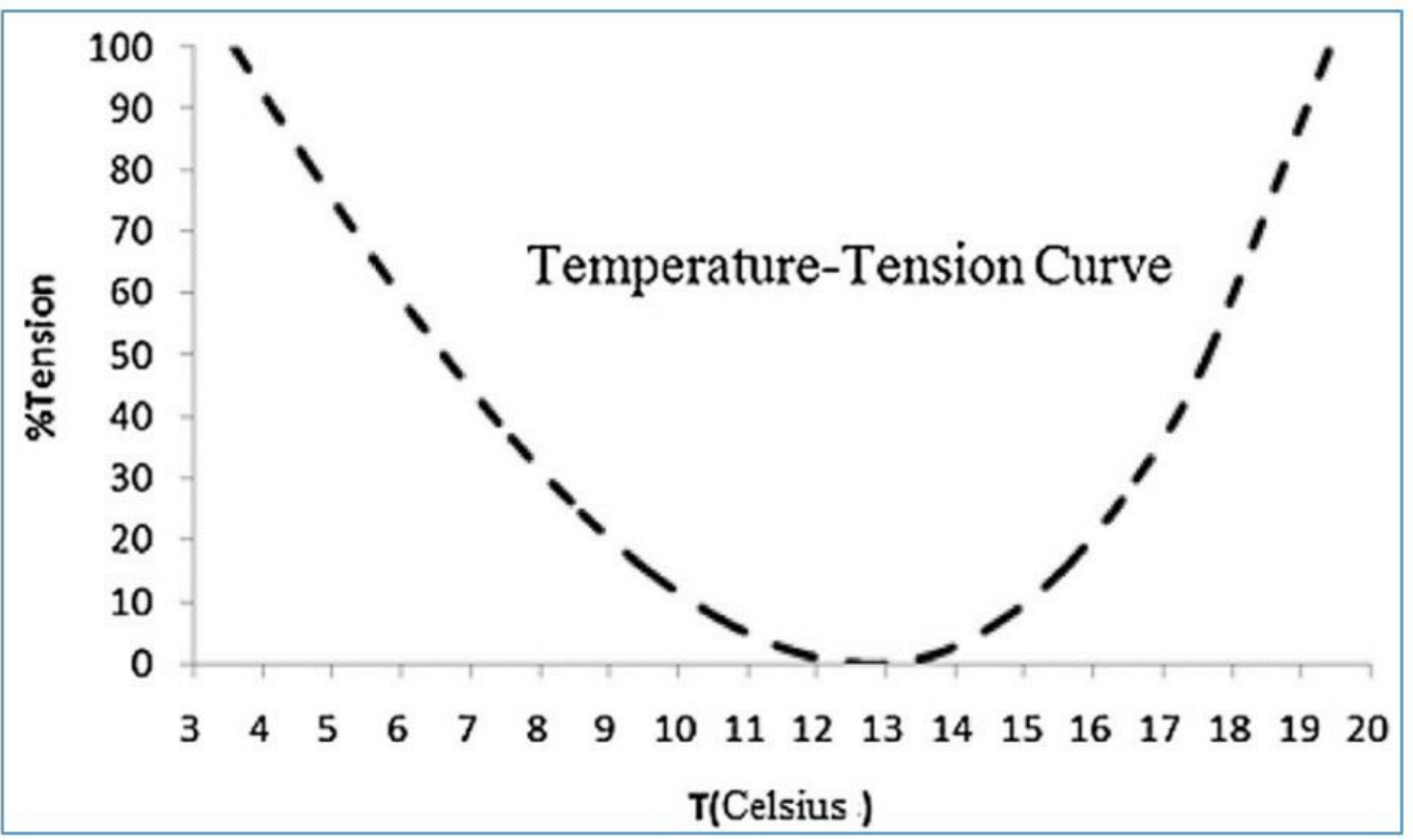

Figure 3

Temperature tension curve developed Sedighkia et,al 2019 


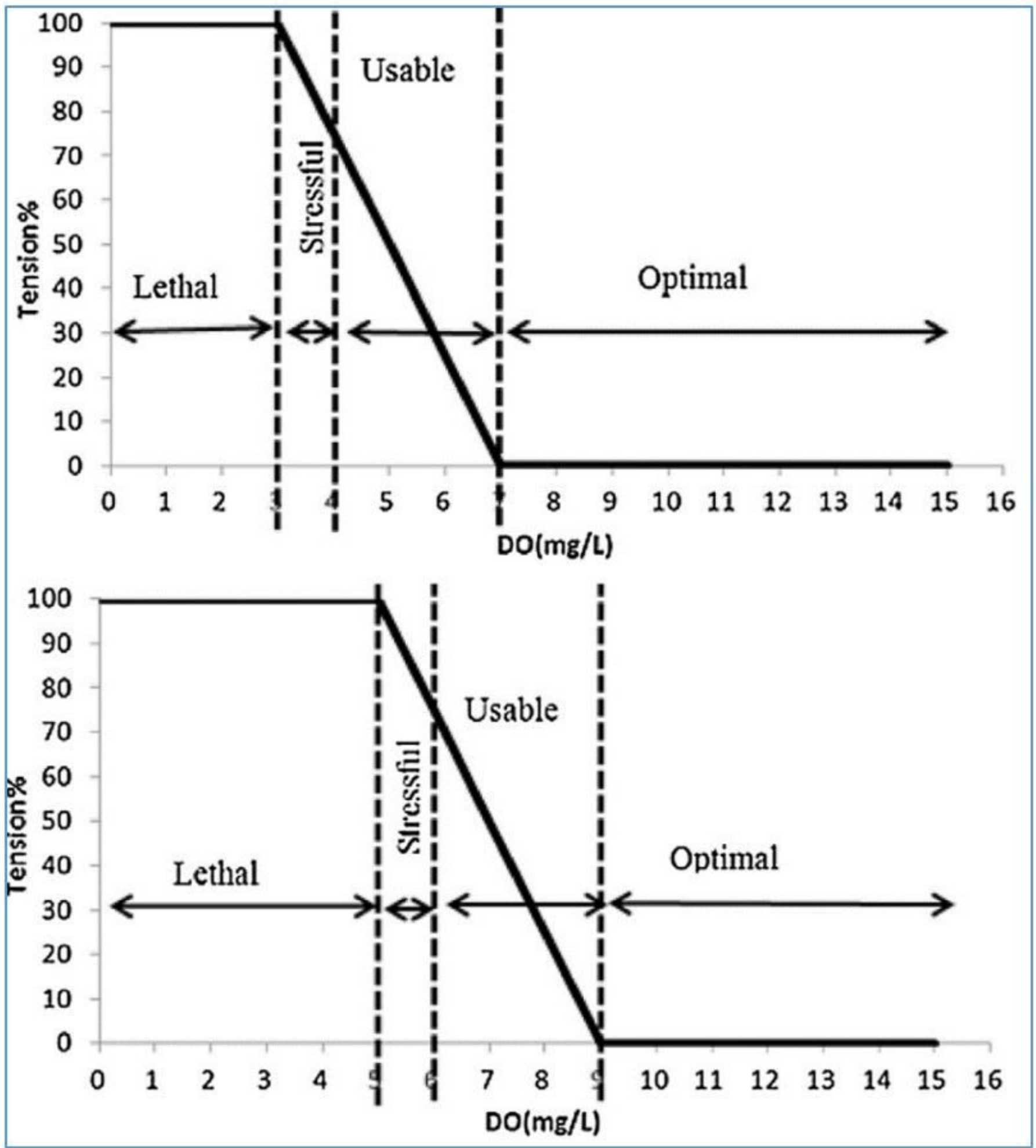

Figure 4

Dissolved oxygen tension curve developed Sedighkia et,al 2019- Up: water temperature<15oc Down: water temperature $>150 \mathrm{c}$ 


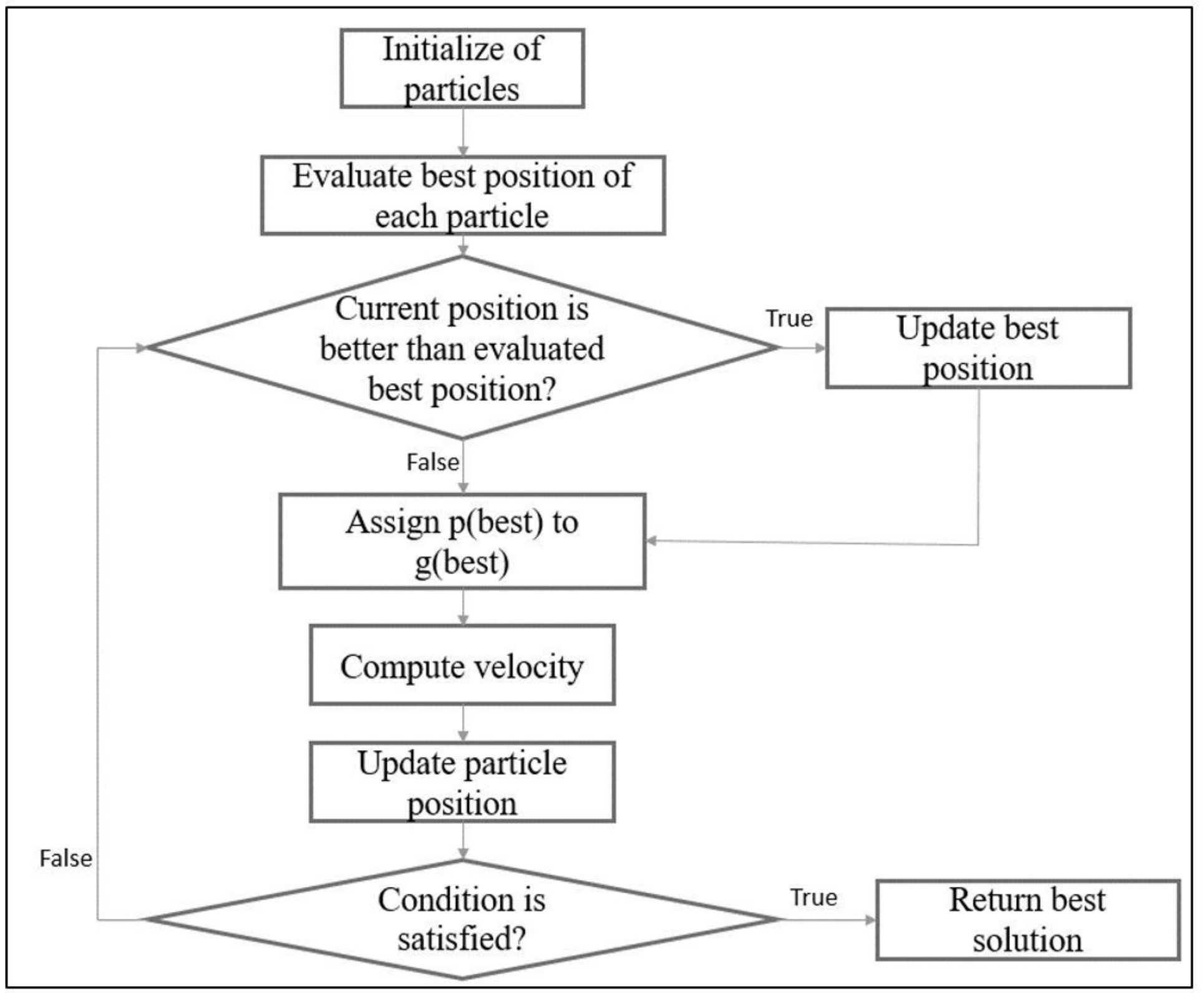

Figure 5

Particle swarm optimization (PSO) flowchart 


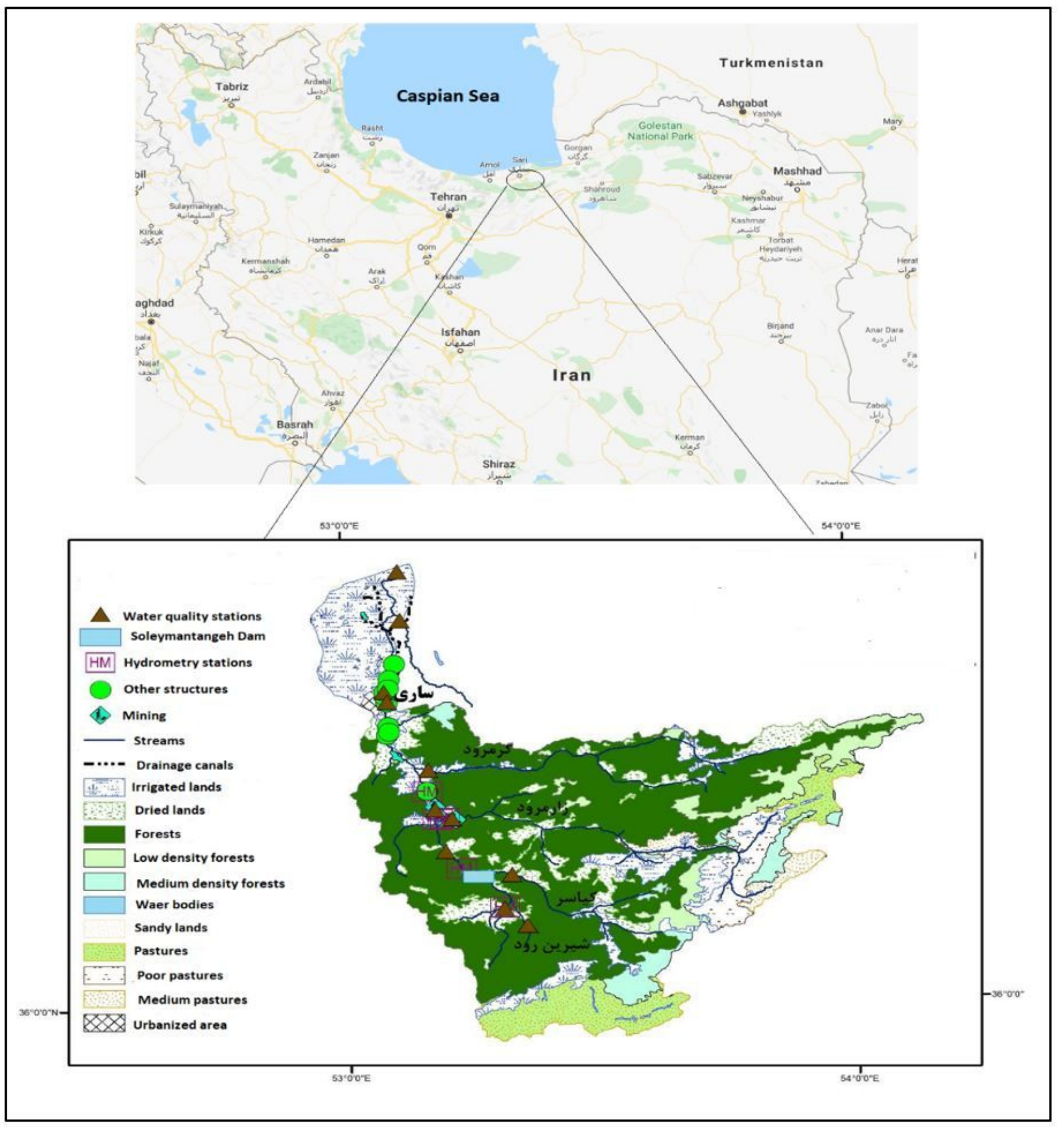

Figure 6

Land use, location of the Rajaei reservoir and river network map of Tajan basin. Note: The designations employed and the presentation of the material on this map do not imply the expression of any opinion whatsoever on the part of Research Square concerning the legal status of any country, territory, city or area or of its authorities, or concerning the delimitation of its frontiers or boundaries. This map has been provided by the authors. 

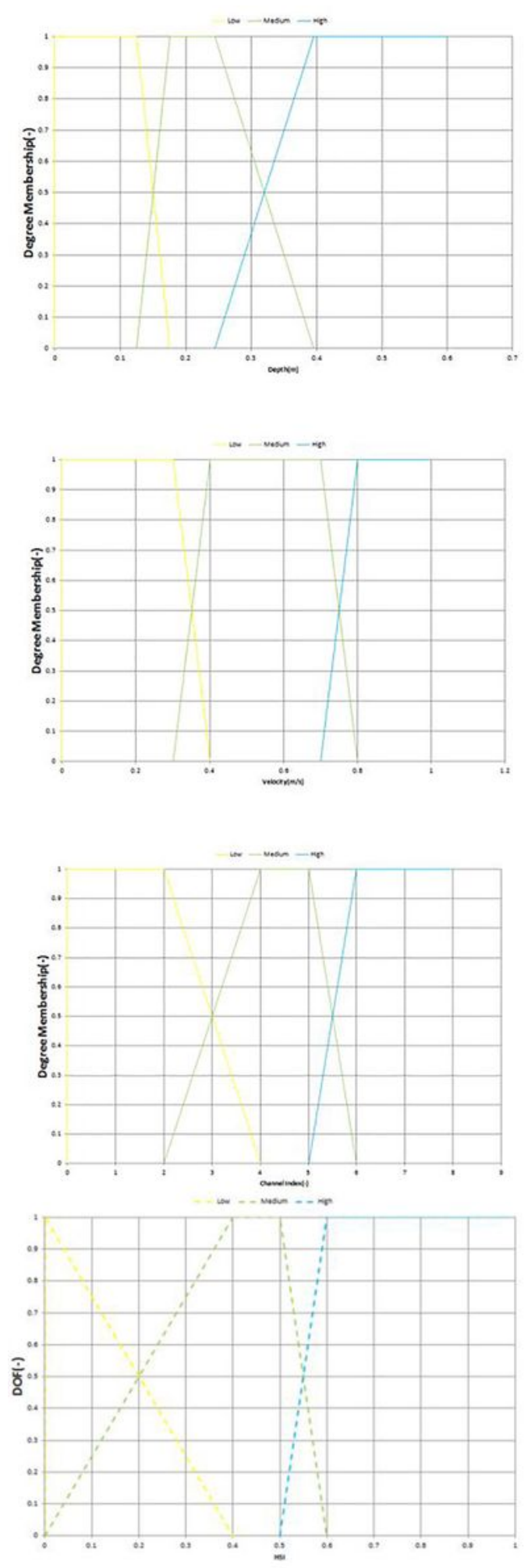

Figure 7

Developed membership functions for the physical habitat model 


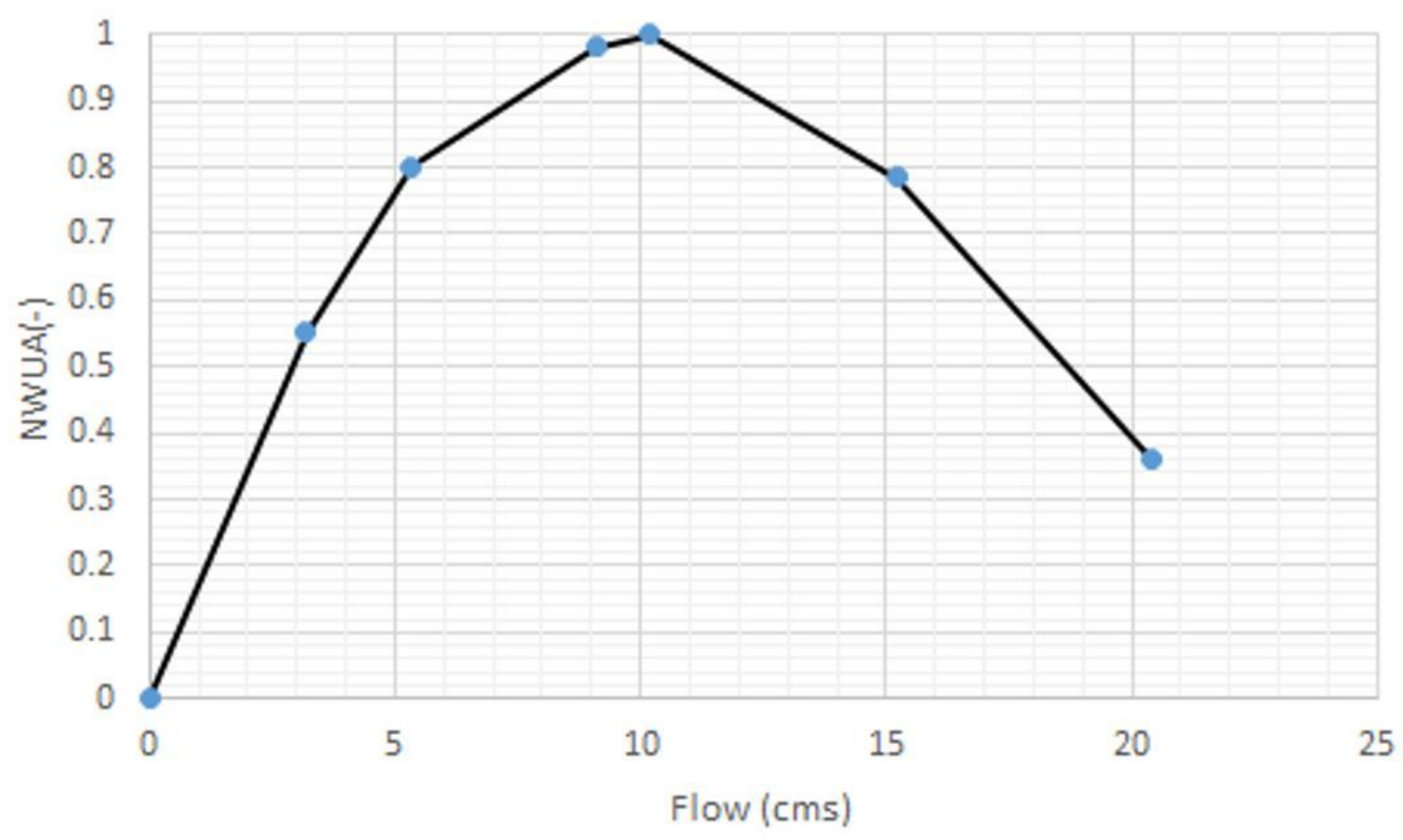

Figure 8

Normalized weighted useable area curve (NWUA)

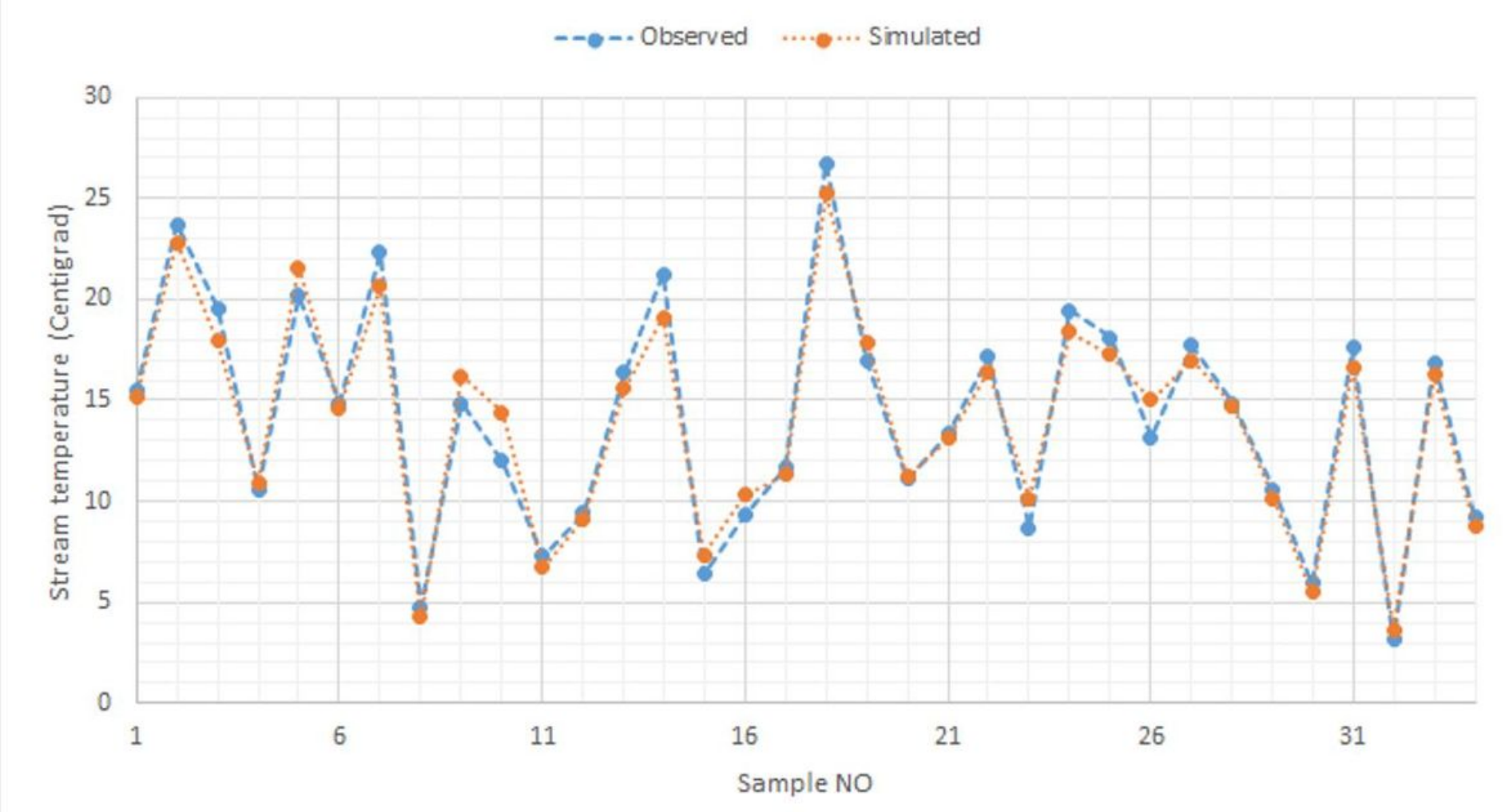


Figure 9

Validation results of the data driven stream temperature model

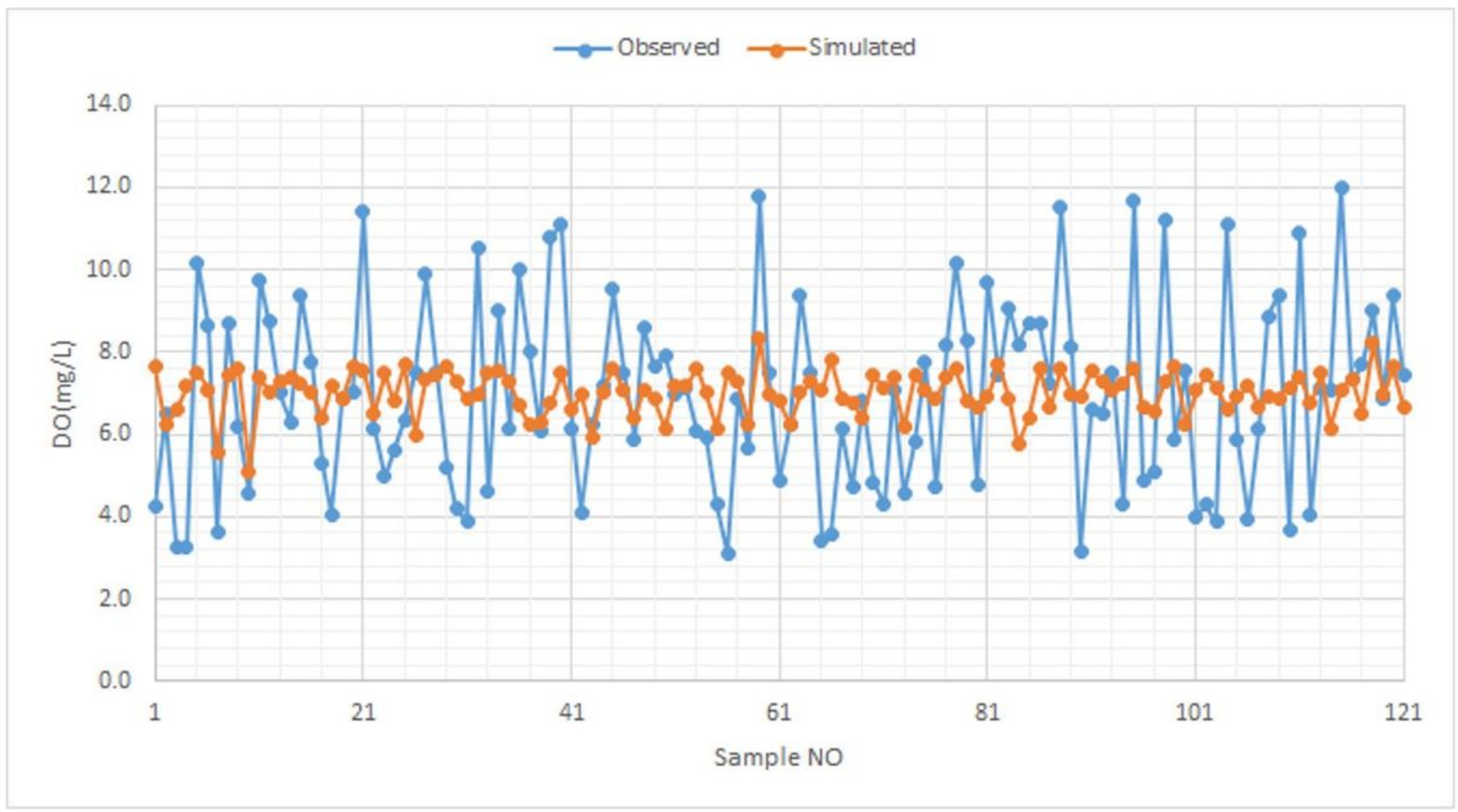

Figure 10

Validation results of the data driven dissolved oxygen model 


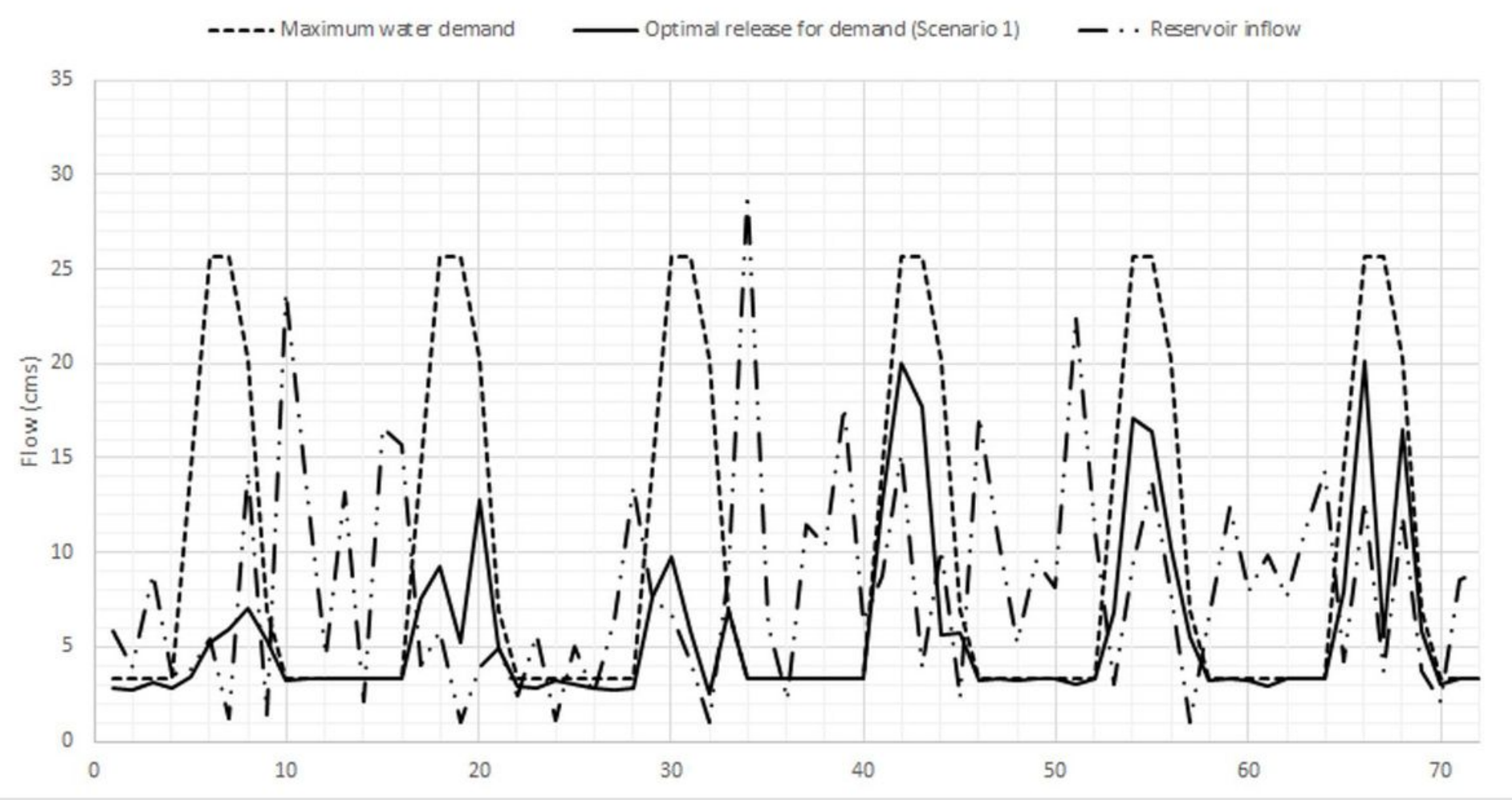

Figure 11

Reservoir inflow, release for demand in the scenario 1 and maximum water demand in the simulated period

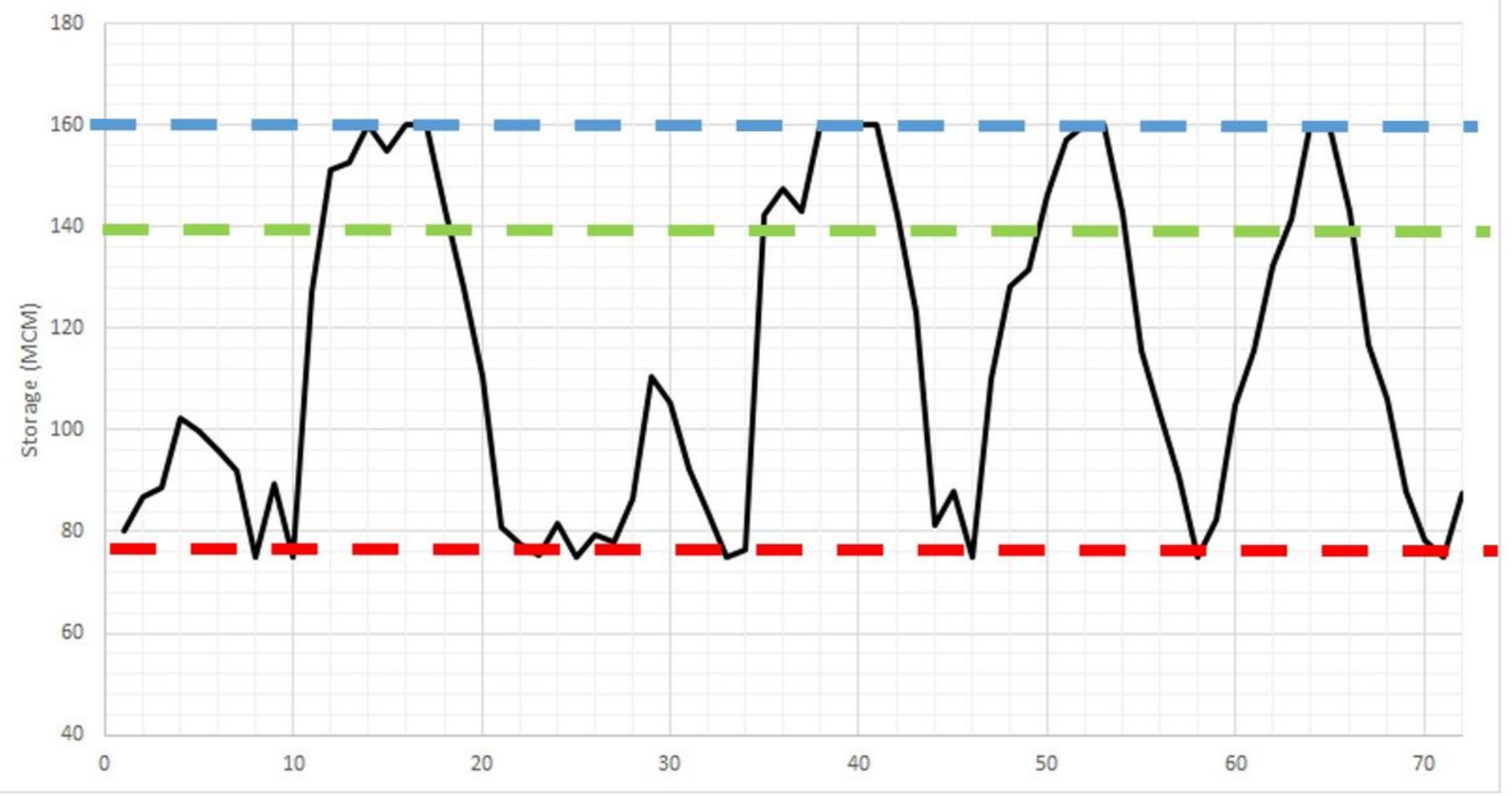

Figure 12 
Storage of the reservoir in the simulated period for the optimization model in the scenario 1

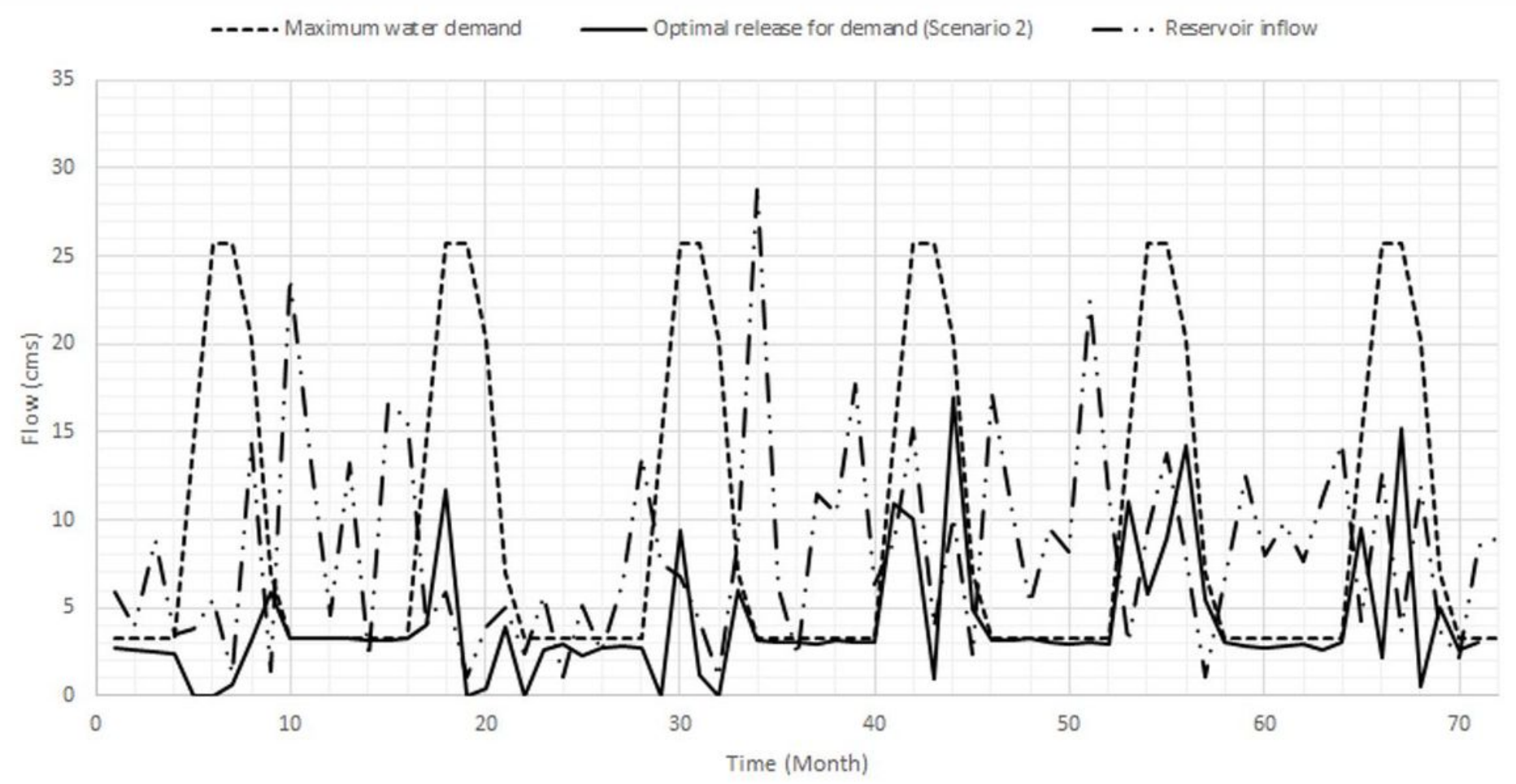

Figure 13

Reservoir inflow, release for demand in the scenario 2 and maximum water demand in the simulated period

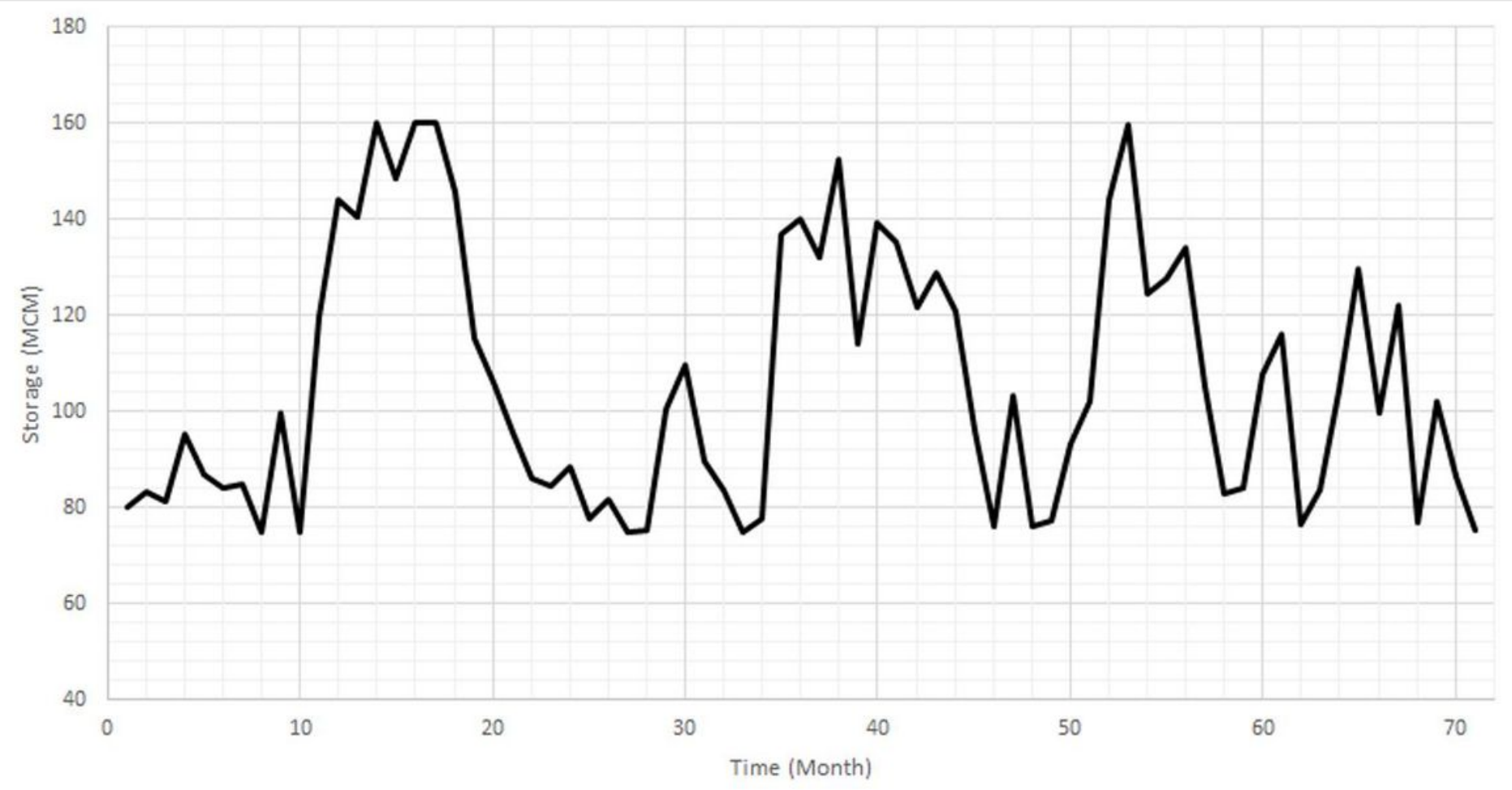

Figure 14 
Storage of the reservoir in the simulated period for the optimization model in the scenario 2

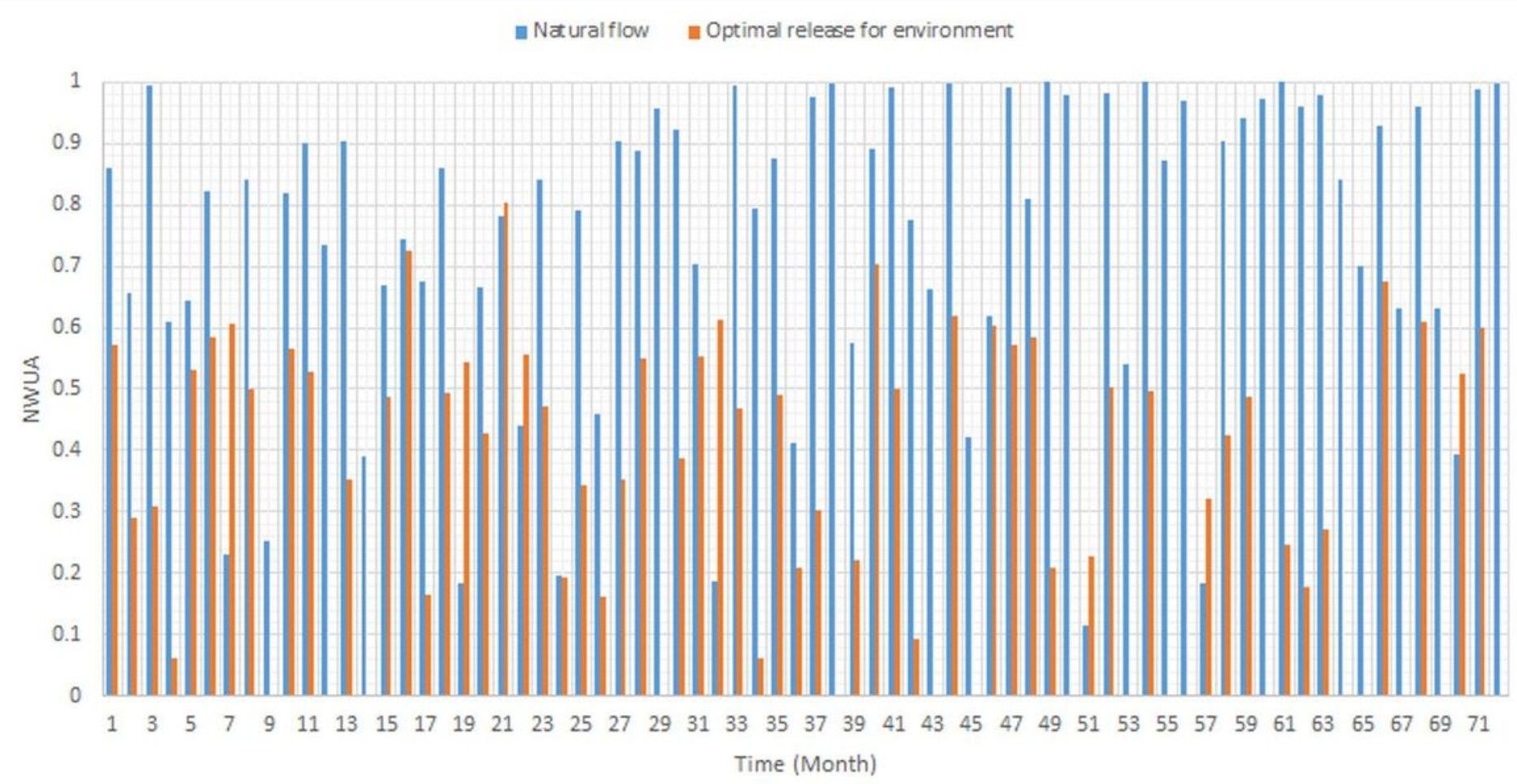

Figure 15

NWUA time series in the simulated period for the optimization model in the scenario 2

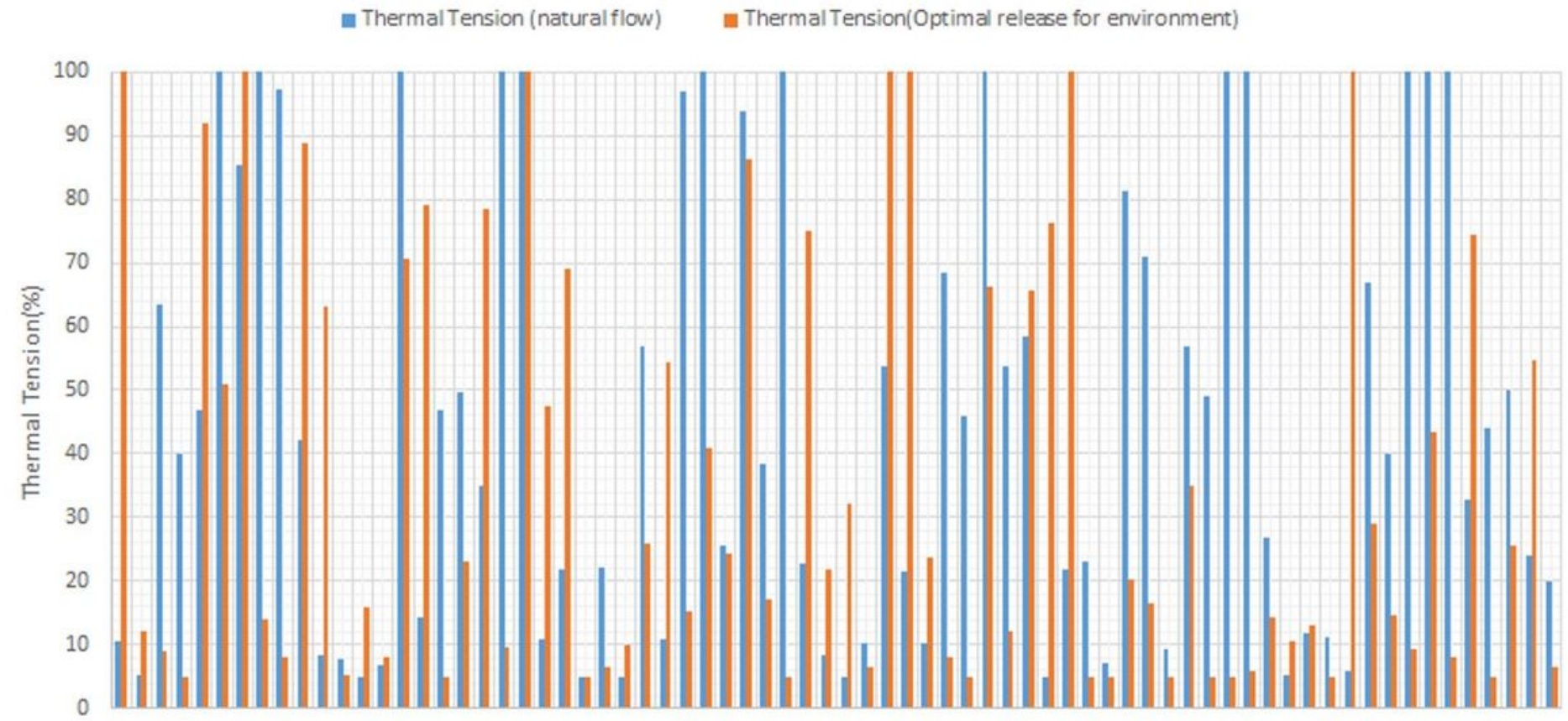

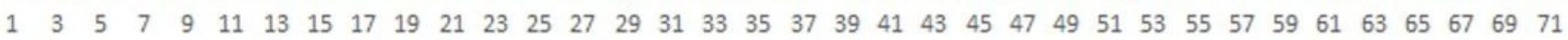

Time (Month)

Figure 16 
Thermal tension time series in the simulated period for the optimization model in the scenario 2

a DO Tension (naturalflow) ㅁ DO Tension scenario 2)

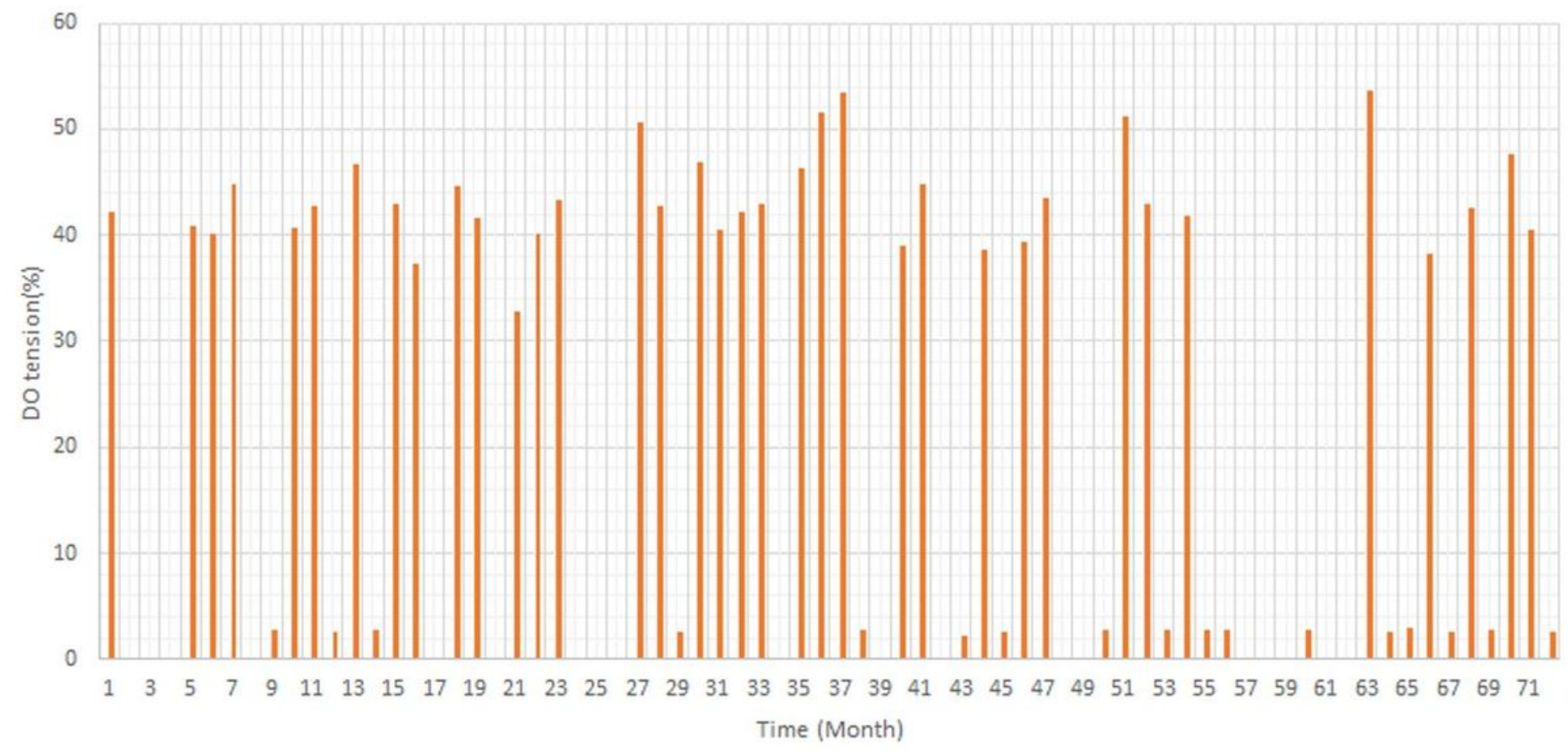

Figure 17

DO tension time series in the simulated period for the optimization model in the scenario 2

\section{Scenario 1 Scenario 2}

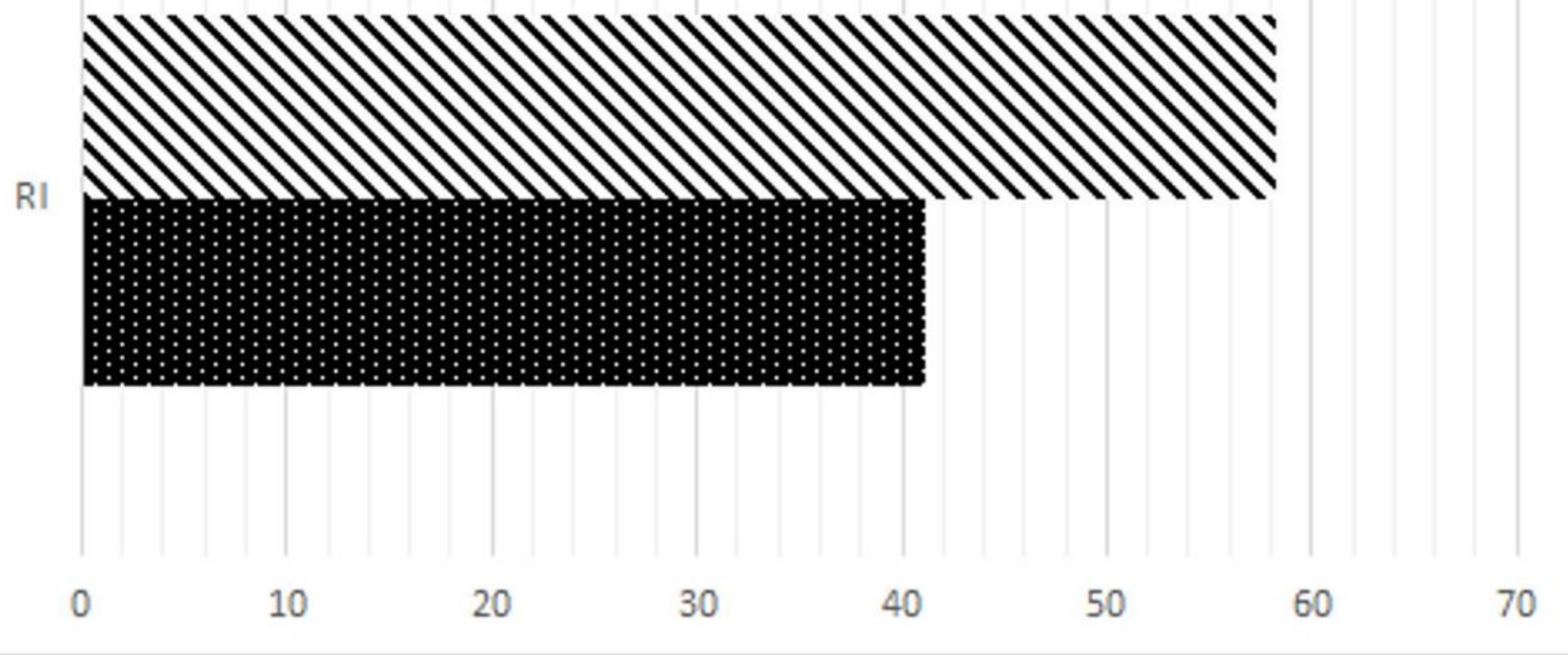




\section{Figure 18}

Reliability index for water supply

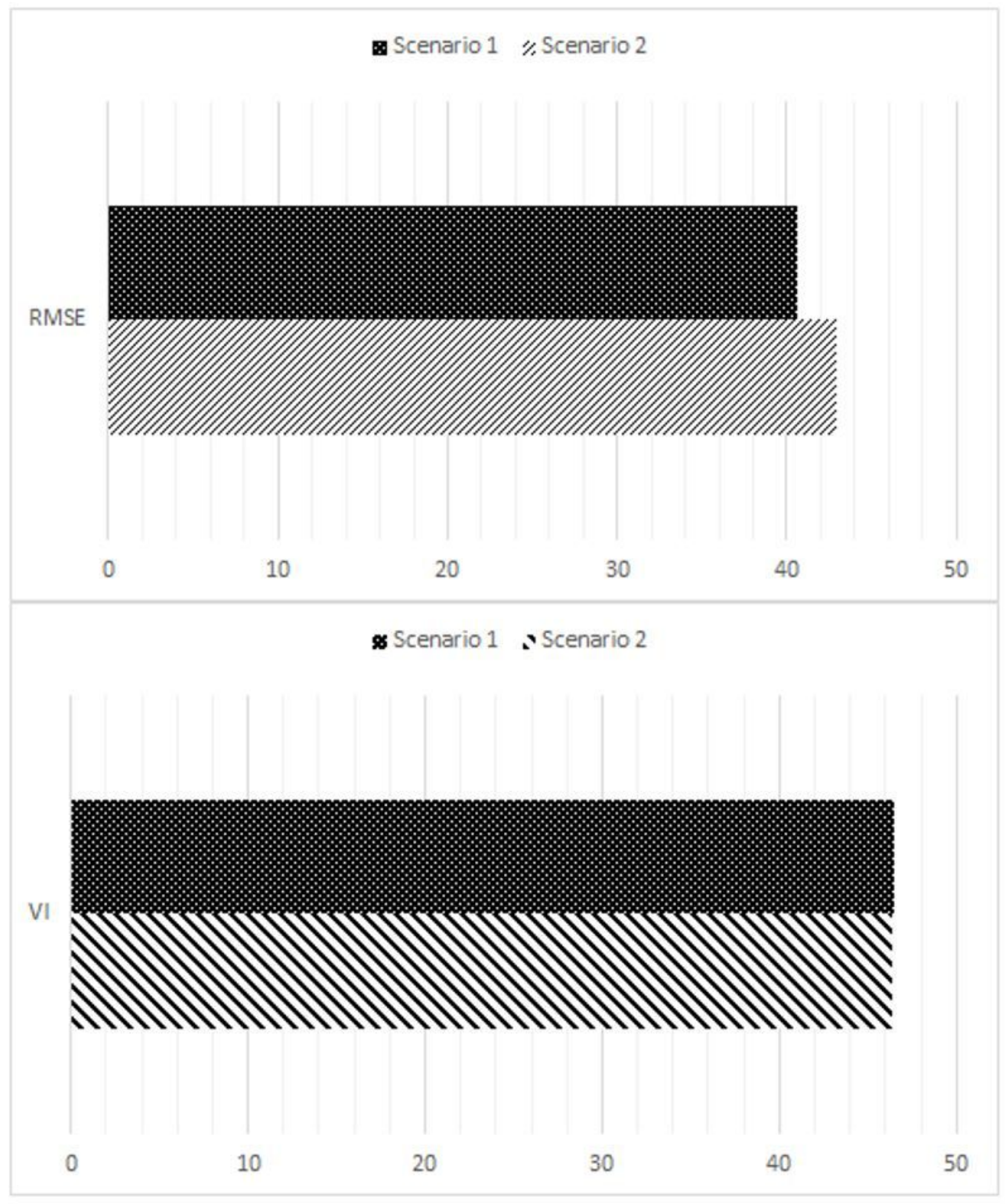

Figure 19

Measurement indices for storage loss 